\title{
Review
}

Evgeny Valerievich Gurentsov*

\section{A review on determining the refractive index function, thermal accommodation coefficient and evaporation temperature of light- absorbing nanoparticles suspended in the gas phase using the laser-induced incandescence}

https://doi.org/10.1515/ntrev-2018-0080

Received February 21, 2018; accepted September 7, 2018; previously published online October 10, 2018

\begin{abstract}
In this review, the possibility of using pulsed, nanosecond laser heating of nanoparticles (NPs) is demonstrated, in order to investigate their thermo-physical properties. This approach is possible because the laser heating produces high NP temperatures that facilitate the observation of their thermal radiation (incandescence). This incandescence depends on the thermo-physical properties of the NPs, such as heat capacity, density, particle size, volume fraction and the refractive index of the particle material, as well as on the heat-mass transfer between the NPs and the surrounding gas media. Thus, the incandescence signal carries information about these properties, which can be extracted by signal analyses. This pulsed laser heating approach is referred to as laserinduced incandescence. Here, we apply this approach to investigate the properties of carbon, metal and carbonencapsulated Fe NPs. In this review, the recent results of the measurements of the NP refractive index function, thermal energy accommodation coefficient of the NP surface with bath gas molecules and the NP evaporation temperature obtained using laser-induced incandescence are presented and discussed.
\end{abstract}

Keywords: evaporation temperature; nanoparticles; pulsed laser heating; refractive index function; thermal accommodation coefficient.

\section{Introduction}

The application of nanoparticles (NPs) in many fields of science and technology is driving an increase in studies

\footnotetext{
* Corresponding author: Evgeny Valerievich Gurentsov, Joint Institute for High Temperatures, Russia Academy of Sciences, 125412 Izhorskaya St. 13-2, Moscow, Russia,

e-mail: gurentsov@ihed.ras.ru
}

addressing the properties of such NPs. Knowledge of the thermo-physical properties of NPs is important for their synthesis and applications. However, the small size of the NPs complicates the measurement of their properties. To address this, novel NP-focused methods are required.

Laser-induced incandescence (LII) is a promising technique in the field of NP diagnostics [1]. Pulsed laser irradiation allows the NPs to be heated to high temperatures (typically higher than $2000 \mathrm{~K}$ ), at which incandescence becomes detectable. However, not all types of NPs can be investigated by LII. Only the refractory NPs, which absorb pulsed laser irradiation, can be studied. The incandescence depends on the thermo-physical properties of the NPs, such as heat capacity, density, particle size, volume fraction and the refractive index of the particle material, as well as on the heat-mass transfer between the NPs and the surrounding gas media.

Usually, for heating of NPs the nanosecond (ns) lasers are applied. The reason for the ns heating of NPs is the much shorter time scale of laser action and the conduction heat transfer of the laser-heated NPs with surrounding gas media in comparison with a time scale of NP formation (hundreds of microseconds). Accordingly, the ns laser pulse allows the diagnosis of NPs of various sizes during the process of their growth.

The common LII model used for particle size or volume fraction evaluation considers the current particle temperature $T_{p}$ during their heating and cooling, using a series of energy and mass balance equations given by Equations (1) and (2) [2]

$$
\frac{\mathrm{d}\left(m_{p} c_{p} T_{p}\right)}{\mathrm{d} t}=\dot{q}_{\mathrm{abs}}-\dot{q}_{\mathrm{rad}}-\dot{q}_{\mathrm{cond}}-\dot{q}_{\text {evap }},
$$

$$
\frac{\mathrm{d} m_{p}}{\mathrm{~d} t}=-J_{\text {evap }},
$$

where $m_{p}$ and $c_{p}$ are the mass and heat capacities of NPs, respectively; $t$ is time; $J_{\text {evap }}$ is the mass loss rate from the particle surface during the evaporation process; $\dot{q}_{\text {abs }}$ is the laser energy per unit time absorbed by the NP; and 
$\dot{q}_{\text {evap }}, \dot{q}_{\text {rad }}$ and $\dot{q}_{\text {cond }}$ are the energy loss rates from the NP during evaporation, thermal radiation and conductive heat transfer, respectively.

During the laser heating of the NPs, the heat capacity of its material is changing. Therefore, the temperature dependencies of the heat capacity for NPs should be used. The current particle mass in Equations (1), (2) is converted to the current particle diameter by using a value of particle density which is, a priory, unknown (bulk material density is usually used).

In the Rayleigh limit $\left(d_{p} \ll \lambda_{\text {laser }}\right)$, the light energy absorption on wavelength $\lambda_{\text {laser }}$ by a NP with a diameter $d_{p}$ can be written as [2]

$$
\dot{q}_{\text {abs }}=\frac{\pi^{2} d_{p}^{3} E(m)}{\lambda_{\text {laser }}} g(t),
$$

where $g(t)$ is the time profile of the laser intensity given by the measured laser profile $g_{m}(t)$ that is normalized and weighted by laser fluence $R_{0}\left[\mathrm{~J} / \mathrm{m}^{2}\right]$

$$
g(t)=\frac{R_{0} g_{m}(t)}{\int g_{m}(t) \mathrm{d} t} .
$$

In Equation (3), $\lambda_{\text {laser }}$ is the wavelength of the heat-up laser, and $E(m)$ is the function of complex refractive index $m=n-i k$ of the particle material given by

$$
E(m)=-\operatorname{Im}\left(\frac{m^{2}-1}{m^{2}+1}\right)=\frac{6 n k}{\left(n^{2}-k^{2}+2\right)^{2}+4 n^{2} k^{2}} .
$$

Usually, the main energy loss during particle cooling proceeds in the free molecular conditions of the particle heat transfer with the surrounding gas at the atmospheric or sub-atmospheric pressures [3] expressed as

$$
\dot{q}_{\text {cond }}=\alpha \pi d_{p}{ }^{2} \frac{P}{2} \sqrt{\frac{8 k_{B} T_{g}}{\pi \mu_{g}}}\left(\frac{\gamma+1}{\gamma-1}\right)\left(\frac{T_{p}}{T_{g}}-1\right) .
$$

In Equation (6), $T_{p}$ is the current NP temperature, $T_{g}$ is the surrounding gas temperature, $k_{B}$ is the Boltzmann constant, $\alpha$ is the thermal energy accommodation coefficient of the gas molecules with the particle surface, $\mu_{g}$ is the molar mass of the bath gas molecules, $P$ is the gas pressure and $\gamma$ is the gas heat capacities ratio.

The evaporation energy flux is defined as [4]

$$
\dot{q}_{\text {evap }}=-\frac{\Delta H_{V}^{\circ}}{\mu_{V}} \frac{\mathrm{d} m_{p}}{\mathrm{~d} t},
$$

where $\mu_{V}$ is the molar mass of the evaporated species, $\mathrm{d} m_{p} / \mathrm{d} t$ is the rate of mass loss and $\Delta H_{V}^{\circ}$ is the enthalpy of evaporation of particle material. It is postulated that the evaporated species are in equilibrium with the particle surface, and the vapor temperature is equal to the particle temperature. Thus, the rate of mass loss can be defined as [4]

$$
\frac{\mathrm{d} m_{p}}{\mathrm{~d} t}=-\pi d_{p}^{2} p_{V} \sqrt{\frac{\mu_{V}}{2 \pi R T_{p}}},
$$

where $R$ is the universal gas constant. The vapor pressure $p_{V}$ above the particle surface is controlled by the ClapeyronClausius equation given by

$$
p_{V}=p_{\text {ref }} \cdot \exp \left(-\frac{\Delta H_{V}^{\circ}}{R}\left(\frac{1}{T_{p}}-\frac{1}{T_{\text {ref }}}\right)\right),
$$

where $p_{\text {ref }}$ and $T_{\text {ref }}$ are the pressure and temperature at the reference point on the evaporation curve, respectively.

For the radiation heat loss from the particle surface in all spectral ranges, the Stephan-Boltzmann law is used

$$
\dot{q}_{\mathrm{rad}}=\pi d_{p}^{2} \varepsilon \sigma_{S B}\left(T_{p}^{4}-T_{g}^{4}\right),
$$

where $\sigma_{S B}$ is the Stephan-Boltzmann constant, and $\varepsilon$ is the integrated emissivity of NP material in the whole spectral range, which is usually assumed to be equal to 1 . Typically, the irradiative cooling rate is significantly (one or more order of magnitude) smaller than the other cooling rates, such as the evaporation and conductive-cooling rate at atmospheric pressure [1]. This is the reason why, for arbitrary particles, the Stephan-Boltzmann Equation (10) for radiative heat flux is assumed to use integral emissivity equal to one (if this value a priory is unknown). For the soot particles, the irradiative cooling rate is described by more complicated expressions presented in [2].

The direct measurement of spectrally-resolved incandescence on two or more wavelengths results in particle temperature evolution (two-color pyrometry). This statement is correct if some suppositions are fulfilled. First, the NP emission/absorption must obey the Planck Law. Second, the assumption is that, the fluence distribution across the laser beam profile is uniform (tophat profile), and all the particles in the laser volume are heated to the same temperature. Third, the attenuation of the LII signal by NP absorption in the detection path is expected to be small. The optical pyrometer derives an effective particle temperature, which is close to the highest particle temperature in the laser-heated volume. The next point is the knowledge of refractive index function variation with wavelength, which shall be discussed below. Finally, the peak temperature of laser-heated 
NPs with known laser fluence can provide the refractive index function of the NP material. Additionally, with the rise in laser fluence, the peak temperature of the laserheated particles approaches their evaporation/sublimation temperature, which is important thermodynamics parameter.

In the common LII technique, the particle volume fraction or particle size distribution are determined, on the one hand, by analyzing the LII signals [5] using the suggested NP properties. The LII signal decrease rate is connected with the thermodynamic properties of the laser-heated NPs. Thus, the incandescence signals comprise the information about these properties, which can be extracted by the signal analysis. On the other hand, the analysis of LII signals could provide the separated NP properties (for example, thermal energy accommodation coefficient), if the particle size distribution and other properties are known. However, in the available LII literature, only a few attempts have been made to determine the NPs' thermo-physical properties using the analysis of LII signals.

In this review, we focus on the measurements of NP properties by the pulsed laser-heating method (known as the LII technique), including the refractive index function of the NP material, the thermal energy accommodation coefficient and the sublimation/evaporation NP temperature. The applicability of this method for future investigations is also analyzed.

\section{The determination of the refractive index function of the NPs}

\subsection{The optical properties of the NPs}

The optical properties of NPs are important characteristics of a material. The emission and absorption of light by NPs critically influence many fields of human industrial activity (e.g. hydrocarbon combustion technologies), the Earth's climate (by the presence of aerosol particles in the atmosphere) and, ultimately, our understanding of the structure of the universe, because interstellar space is full of nano-dispersed materials. The interaction of visible and near infrared light with NPs proceeds in the Rayleigh limit (Equation (3)), where the energy is absorbed by a whole NP volume.

Practically all methods of NP monitoring (e.g. dynamic light scattering, laser light extinction and LII) are based on their optical properties, which are represented by the complex refractive index of the particle material. The function $E(m)$, which is based on the value of complex refractive index, is used in the LII models to account for the part of laser energy absorbed by particles. Thus, the reliable knowledge of the refractive index function of NPs is of great importance for optical diagnostics and others applications. The function $E(m)$, based on the value of the complex refractive index, is used to account for the part of laser energy absorbed by particles and for determination of NP emissivity (Equation (12)). However, knowledge of these properties for arbitrary particles based on particle refractive indexes is quite scant. Nevertheless, massive amounts of optical property data are available for soot particles due to their importance in irradiative heat exchange in combustion and as an atmospheric pollutant $[6,7]$.

The theoretical analysis of the optical properties of NPs is difficult because it exhibits structural inhomogeneities at all length scales. This is especially true of carbonaceous NPs, which are usually built from the atoms with various hybridizations [8-10]. The optical properties of metal-based NPs might vary with temperature, particularly at the points of second-order phase transitions and at the transitions from one allotropic modification to another [11]. With decreasing NP size, the quantum effects might occur related to the electron zone variation and to the occurrence of the separated electron levels, which should inevitably influence electrical conductivity and optical properties. Despite much progress in the calculation technique, such as the molecular dynamics method that can predict the optical properties of the nano-objects [12], direct experimental measurements are, in our opinion, the highest priority. A comparison of the experimental and calculated data makes it possible to analyze the adequacy of the engaged models and to develop new calculation approaches. Moreover, the optical properties are influenced by NP aggregation, which is an a priori unknowable characteristic [13]. Thus, the experimental investigations of optical properties of nano-objects are preferable to theoretical calculations, and these could also be used to validate the existing models.

\subsection{The methods of determining the optical properties of NPs}

The experimental methods for the determination of NPs' optical properties have a long history, starting with the ex situ methods. In earlier studies, the optical constants of 
soot were calculated from the intensity of polarized light reflected from the surface. Among experimental data on optical properties of soot, the ex situ reflectometry measurements of Dalzell and Sarofim [14] and Felske et al. [15] provide the direct values of refractive indexes for combustion soot. However, these methods require special sample preparations. The above reflectance measurements, as well as ellipsometric intensity measurements [16], utilize soot pellets produced by modification by 40,000 psi (275 $\mathrm{Mpa}=2750$ bar) material, which can change the soot's structure and properties. Changes in the measurements of scattering cross-section could be caused by changes in the morphology of the aggregate, such as an increase in the radius of gyration or a decrease in the fractal dimension.

The in situ determination of the refractive index of soot was carried out, for example, from the extinction measurements of Köylü and Faeth [17] in the visible and infrared ranges. Furthermore, the absorption and scattering measurements in the visible range were used for the soot refractive index evaluation by Wu et al. [18] and by Krishnan et al. [19]. The reflectance and transmission spectra can be obtained directly from the aerosol samples as a function of wavelength. The effective real and imaginary components of the refractive index of the material can be approximated, as a function of wavelength, from the measured spectra [20, 21].

The variation of extinction measurements is the lineof-sight attenuation (LOSA), which is typically used for spatially resolved soot concentration diagnostics [22]. Concerning the subject of this review, the data on the extinction coefficient measurements obtained by LOSA for $\mathrm{Cu}$ and $\mathrm{Si}$ NPs are presented in [23] and compared with the electrical permittivity data calculated by Drude theory. Notably, the extinction coefficients were presented in the visible and near infrared range of the spectra, thus facilitating the determination of the $E(m)$ ratio at different wavelengths in two-color or spectra-resolved temperature measurements of laser-heated NPs.

In the above-mentioned measurements, estimations of the scattering/absorption cross-section ratio require knowledge of the structure of the soot aggregates [24, 25], which is a priori unknown. The large uncertainties of such measurements and the interpretation of the optical properties are also connected with the non-spherical morphology of soot, the variability of its fine structure and composition as it ages and the wide range of conditions under which measurements have been performed. Nevertheless, an advantage of the above methods is that the broadband measurements are made across a wide range of spectra using non-laser light sources.

\subsection{The method of measuring the refractive index function by pulsed laser heating}

The method for measuring optical properties, as discussed in this paper, concerns the refractive-index function $E(m)$, which is critical for calculating the light absorption of NPs, NP emissivity and other optical coefficients. The method is an in situ method based on laser heating. A major advantage of laser heating (compared with extinction or scattering measurements) is that no knowledge of the aggregate structure or primary particle size is needed. The disadvantages include the need to use only laser wavelengths and the determination of the refractive index function without dividing it into real and imaginary parts.

In the Rayleigh limit, when the NP size is much less than the laser wavelength, the energy absorption by the NP occurs volumetrically, without any temperature gradients inside the particles [1] and at a ns timescale. The maximal temperature attained at the pulsed laser heating of the NP is directly proportional to the $E(m)$, as long as sublimation and other effects do not play a role. The twocolor pyrometry allows the maximal temperature to be calculated from the experimental traces of incandescence intensities at two different wavelengths in the visible spectral range, which is rationed using the Planck radiation formula [26] given by

$$
T_{p}^{0}=\frac{h c}{k_{B}} \frac{\left(\frac{1}{\lambda_{2}}-\frac{1}{\lambda_{1}}\right)}{\ln \left[\frac{I_{1}}{I_{2}} \frac{I_{T L_{2}}}{I_{T L_{1}}} \frac{\varepsilon\left(\lambda_{2}\right)}{\varepsilon\left(\lambda_{1}\right)}\right]+\frac{h c}{k_{B} T_{T L}}\left(\frac{1}{\lambda_{2}}-\frac{1}{\lambda_{1}}\right)},
$$

where $h, c$ and $k_{B}$ are the Planck constant, speed of light in vacuum and Boltzmann constant, respectively; $\lambda_{1}$ and $\lambda_{2}$ are the registered radiation wavelengths; $I_{1}$ and $I_{2}$ are the maximum amplitudes of the registered LII signals; $I_{T L L}$, $I_{T L 2}$ and $T_{T L}$ are the radiation intensities and the brightness temperature of the calibration tungsten strip lamp defined by the manufactured pyrometer and tungsten spectral emissivity on the wavelengths $\lambda_{1}$ and $\lambda_{2}$ and $\varepsilon\left(\lambda_{1}\right)$, respectively, and $\varepsilon\left(\lambda_{2}\right)$ are the NP spectral emissivity at wavelengths $\lambda_{1}$ and $\lambda_{2}$ [2] computed as

$$
\varepsilon(\lambda)=\frac{4 \pi d_{p} E(m)}{\lambda} .
$$

Neglecting the heat losses by conductivity, evaporation and thermal radiation, the peak temperature of the laser-heated NP $T_{p}^{0}$ could be obtained by the integration of Equation (1) [27] 


$$
T_{p}^{0}=T_{g}+\frac{6 \pi \cdot R_{0} \cdot E(m)}{\rho_{p} \cdot c_{p} \cdot \lambda_{\text {laser }}}
$$

Here, $\rho_{p}$ and $c_{p}$ are the NP density and heat capacity, respectively; $T_{g}$ is the temperature of the surrounding gas; $R_{0}$ is the integrated laser fluence and $\lambda_{\text {laser }}$ is the laser wavelength. The final value of $E(m)$ could be determined from expressions (11) and (13) by fitting the data of the two above-mentioned methods of the particle heat-up temperature determination.

This method requires the refractive index function wavelength dependence, which is typically unknown for NPs and should be measured or assumed [see Equations (11) and (12)]. Thus, the $E(m)$ wavelength dependence is the main uncertainty of the absolute value of $E(m)$ measurements using pulsed laser heating.

Concerning the $E(m)$ measurements of flame soot, the linear wavelength dependence in the visible and near infrared are typically assumed, following the experimental studies of Krishnan et al. [24] and Snelling et al. [28]. For example, the data of $E(m)$ as a function of the wavelength presented by Krishnan et al. [24] resulted in $E(m)_{760 \mathrm{~nm}} / E(m)_{488 \mathrm{~nm}}=1.12$, and the data of Chang and Charalampopoulos [29] led to the $E(m)_{760 \mathrm{~nm}} / E(m)_{488 \mathrm{~nm}}=0.84$, which corresponds to the deviation of $\pm 6 \%$ from measured peak particle temperature values. As gathered from the literature, the proposed $E(m)$ dependences on wavelength for the soot particles are summarized in [30]. When shorter distances between diagnostics wavelengths are used for this measurement, the inaccuracy is reduced. Thus, the $E(m)$ wavelength dependence of the arbitrary NPs should be carefully considered when using the pulsed laser-heating method. All available data should be considered. However, in the absence of such data for arbitrary particles, the variations of $E(m)$ with wavelength can be neglected in the visible spectral range. For better accuracy, the use of proximal wavelengths for two-color measurements is recommended. Usually, the LII measurements are carried out in the visible range of the spectra. For the two-color LII, the common wavelengths for the temperature measurements are 450 and $800 \mathrm{~nm}$. Using these wavelengths one can obtain the minimal error in temperature measurements using the Planck Law. However, using closer wavelengths, for example, 600 and $800 \mathrm{~nm}$, the uncertainty of temperature measurements will not essentially increase due to the application of the Planck Law, but will decrease because of the smaller uncertainty in the wavelength dependence of $E(m)$.

\subsection{The results obtained by the pulsed laser-heating method}

\subsubsection{Soot particles}

A few recent studies have addressed the determination of $E(m)$ for soot particles based on LII measurements. These results are presented in Table 1. Snelling et al. [27] reported the value of $E(m)=0.42$ for $1064 \mathrm{~nm}$ from a pyrometric measurement of the soot peak temperature in a diffusion flame under the assumption of a wavelength-independent absorption function and $E(m)=0.395$ when using a linear dependence of $E(m)$ on $\lambda$. Later, a value of 0.4 was obtained for laser excitation at $532 \mathrm{~nm}$ [31]. De Iuliis and co-authors reported a value of $E(m)=0.29$ at $1064 \mathrm{~nm}$ in a diffusion flame [32]. Eremin and co-authors [33] observed growing carbon particles during the acetylene pyrolysis behind a shock wave. Small carbon particles of about 1-14 $\mathrm{nm}$ in diameter had a low value of $E(m)$ at a wavelength of $1064 \mathrm{~nm}(-0.05-0.07)$, which may increase up to a value of $0.2-0.25$ during particle growth (up to $20 \mathrm{~nm}$ ). Most results of the $E(m)$ determination of carbon NPs are in a good agreement with the reported values obtained by extinction measurements, which are in the range of 0.190.47 in the visible wavelength $[7,24,30,34-36]$ at $1064 \mathrm{~nm}$, depending on particle size and maturity.

\subsubsection{Non-soot particles}

Among non-soot NPs, attempts to measure $E(m)$ by pulsed laser heating are presented only for Fe NPs [33] (Table 2). However, the LII measurements of the size distribution

Table 1: The refractive index function values of soot particles measured by pulsed laser heating.

\begin{tabular}{llrr}
\hline $\mathbf{N}$ & Conditions & $\boldsymbol{E}(\boldsymbol{m})$ & References \\
\hline 1 & Diffusion flame, $1064 \mathrm{~nm}$, soot & $0.395-0.42$ & Snelling et al. [27] \\
2 & Diffusion flame, $532 \mathrm{~nm}$, soot & 0.4 & Snelling et al. [31] \\
3 & Diffusion flame, $1064 \mathrm{~nm}$, soot & 0.29 & De luliis et al. [32] \\
4 & Shock tube, $1064 \mathrm{~nm}$, carbonaceous particles 1-20 nm & $0.05-0.25$ & Eremin et al. [33] \\
\hline
\end{tabular}


Table 2: The refractive index function values of non-soot particles measured by pulsed laser heating.

\begin{tabular}{llll}
\hline $\mathbf{N}$ & Conditions & $\boldsymbol{E}(\boldsymbol{m})$ & Reference \\
\hline 1 & Photolytically formed Fe particles $1-12 \mathrm{~nm}, 1064 \mathrm{~nm}$ & $0.1-0.2$ & Eremin et al. [33] \\
\hline
\end{tabular}

of NPs apart from Fe NPs have been carried out in recent years. The spectroscopic models of silicon and copper NPs $[23,37,38]$, as well as the spectroscopic models for Ag, Fe and Mo NPs have been presented [39]. These models are based on the calculations of the electrical permittivity of the molten bulk material in dependence on the wavelength performed using Drude theory. These calculations were supported by the ellipsometry measurements of the molten bulk material. The results of the extinction coefficient measurements obtained by LOSA for $\mathrm{Cu}$ and Si NPs in [23] are in good agreement with the data calculated by Drude theory. These data are not included in the Table 2, because these are not obtained by pulse laser-heating method.

In [33], Fe NPs were synthesized from supersaturated Fe vapor generated by the laser-pulse photolysis of $\mathrm{Fe}(\mathrm{CO})_{5}$ at room temperature, similar to [40]. Time-resolved laserinduced incandescence measurements were carried out for Fe NP sizing using the LII model presented in [41]. Thus, in [33], the values of $E(m)$ at wavelength $1064 \mathrm{~nm}$ were found to be from $\sim 0.1$ for particles $1-3 \mathrm{~nm}$ in diameter up to $\sim 0.2$ for particles $>12 \mathrm{~nm}$ in diameter. It should be noted that the value reported in [42] for the bulk Fe is $E(m)_{1064}=0.1$. When heating Fe NPs by a laser pulse, the temperature attained 2000-3000 K, and the particles entered the molten phase. In [43], the authors presented data of $E(m)$ for molten bulk Fe obtained by ellipsometry [44-46] measurements and through calculations using Drude theory [47]. According to these data, the values for $E(m)$ as a function of wavelength decrease from 0.3 at $300 \mathrm{~nm}$ down to 0.07 at $1100 \mathrm{~nm}$. Thus, at $1064 \mathrm{~nm}$, these data are not correlated with the measurements in [33], presumably due to the data presented in [43] being related to the bulk material and the data in [33] being representative of NPs. Later, the authors of [43] have reconsidered their calculations of molten Fe optical properties as a function of wavelength and have concluded that Drude's theory is not suitable for describing the optical properties of molten Fe [48]. In [39], the authors supposed that the dielectric properties of bulk metals could be applied directly to the NPs because the NP diameter is much larger than the mean free electron path. Thus, the spectral absorption cross-section of metal NPs is identical to that of the bulk material. However, in fact, the real NP shape and aggregation is strongly affected by their dielectric properties and, therefore, also their optical properties. Therefore, the calculated values of spherical isolated metal NP optical properties may differ from the optical properties of real NPs.

\subsection{The peculiarities, benefits and future directions of determining the optical properties of NP by pulsed laser heating}

An action of laser irradiation on the particles could result in changing their properties. For the carbon NPs, a process of annealing under the pulsed laser heating has been proposed in [2], wherein Vander Wal and co-authors have shown the soot particle transformation (graphitization and hollow shells ensue) under $1064 \mathrm{~nm}$ laser heating with fluence of $0.1 \mathrm{~J} / \mathrm{cm}^{2}$ [49-52]. The particles might change their structure if annealing occurs. Michelsen et al. [30] used LII and extinction measurements to derive the scattering and absorption cross-section of soot in dependence on laser fluence. These authors found that the soot absorption cross-section increased with increasing fluence, until the point at which the particle starts to sublime and the scattering cross-sections begin to decrease with increasing fluence. The increase in absorption cross-section was attributed to changes in density with temperature or a change in the optical properties of the particle.

Recently, an effect of annealing processes on the optical properties of in-flame soot has been investigated in [53]. The optical measurements were performed with a two-pulse LII system, where soot was pre-heated with the first pump pulse, and the time-resolved LII signal after the consecutive probe pulse was analyzed. The annealing model developed in [53] appears to contradict the experimental outcome presented. This model assumed that soot begins to anneal at temperatures as low as flame temperature, whereas experiments showed that annealing starts above $4000 \mathrm{~K}$. The model suggests that annealing leads to a reduction in the absorption and emissivity characteristics of soot, whereas experiments indicated a noticeable enhancement of such optical properties once soot was annealed. One possible explanation of laser action on the optical properties of soot has been presented in [54]. Using high-speed images, they found that, at high 
fluence $\left(>0.3 \mathrm{~J} / \mathrm{cm}^{2}\right)$, a much larger region is affected than the directly heated volume. The temperature, soot volume fraction and the emissivity of soot particles are subjected to change in the neighboring regions due to the laser-heated volume. The energy transferred from the particles to the surroundings heat up the bath gas, and the equilibrium between the particles and the bath gas is established at a higher temperature than in the pre-laser state. The total energy transferred is proportional to the soot volume fraction. Therefore, the temperature gain of the bath gas is greater in the flame edge zone than in other areas. The elevated temperatures may change the emissivity of soot. This contributes to the uncertainty of the soot volume fraction and temperature measurements. The findings demonstrate that laser heating for LII measurements is invasive to the flame and soot and should be considered when analyzing LII data, particularly when coupling different measurements.

Additionally, during rapid heating, the particles could evaporate under high laser fluences. The ability of soot to evaporate under pulsed laser heating was first noted by Eckbreth in 1977 [55]. After that, some evidence of laser evaporation of soot were reported in the literature [56-61]. Michelsen et al. reported about producing new particles by laser irradiation of soot at 532 and $1064 \mathrm{~nm}$ [60]. These new particles are produced at fluences above $0.12 \mathrm{~J} / \mathrm{cm}^{2}$ at 532 and $0.22 \mathrm{~J} / \mathrm{cm}^{2}$ at $1064 \mathrm{~nm}$. Finally, at high laser fluences, the optical properties of the carbonaceous particles could be changed, due to their transformation during laser heating, which can influence the accuracy of $E(m)$ determination of primary particles. The conclusion is that the laser-heating method of $E(m)$ determination does not work at high laser fluences and should be carefully applied over $0.1 \mathrm{~J} / \mathrm{cm}^{2}$ with the evaporation control. For example, the recent data by Cenker and Roberts [53] showed that the sublimation of in-flame particle starts at a laser fluence of $<0.1 \mathrm{~J} / \mathrm{cm}^{2}$, which corresponds to a heat-up temperature of $3000 \mathrm{~K}$. At a laser fluence of $0.33 \mathrm{~J} / \mathrm{cm}^{2}$, the mass loss of the particle due to sublimation is measured as $55 \%$ of its initial mass.

From the results of the $E(m)$ measurements by the abovementioned pulsed laser-heating method, one can conclude that these data are related only to wavelengths of 532 and $1064 \mathrm{~nm}$ and correlate with the measurements in flames by other in situ methods (light extinction, light scattering), and thus could be used in engineering calculations. The measured values vary depending on particle size, type of reactor (flame or shock tube) and, consequently, the surrounding conditions (temperature, pressure, gas composition), resulting in the formation of particles with different morphologies, structures and compositions. The benefit of the laser-heating method of optical properties is that it does not require knowledge of particle size and the structure of aggregates, which are necessary for other in situ methods, such as extinction and scattering.

The optical properties of arbitrary particles are different from bulk properties. Moreover, the NPs synthesized from the same material, but having various sizes or structures can have different optical properties, which could be measured in situ by the pulsed laser-heating method. Future studies could focus on the optical properties measurements of the various laser wavelengths and the development of other laser-heating methods. This development could address the application of two excitation laser wavelengths in the experiments for the auto-correction of the wavelength dependence of $E(m)$ for arbitrary particles, as was done in [62]. A past study [62] reported that the ratio of $E(m)_{1064} / E(m)_{532}$, which is $0.98-1.15$, depends on the fuels in the flame, as well as the height above the burner.

\section{The determination of the thermal accommodation coefficient of gas molecules with NP surface by pulsed laser heating}

\subsection{The free molecular heat exchange of NPs with surrounding gases and thermal energy accommodation coefficient determination}

When the mean free molecular path of the gases is greater than or equal to the NP sizes, the heat conduction between NPs and the surrounding gases occurs in a free molecular regime [3]. Under these conditions, the thermal accommodation coefficient $(\alpha)$ is a key parameter of the particle cooling mechanism. The thermal accommodation coefficient describes the extent to which gas molecules exchange vibrational, rotational and translational energy with a particle surface. The value of $\alpha$ is defined as [63]

$$
\alpha=\frac{T-T_{g}}{T_{s}-T_{g}},
$$

where $T$ is the temperature of gas molecules after the energy exchange, and $T_{s}$ and $T_{g}$ are the temperatures of the surrounding medium and particle surface, respectively. From Equation (14), it follows that, when gas molecules 
are fully equilibrated with the surface, $\alpha$ is equal to 1 . Otherwise, when the gas molecules do not gain energy from the surface, the value of the thermal accommodation coefficient is equal to 0 . The accommodation coefficient depends on the type of bath gas, gas temperature and surface temperature [64-66].

It is straightforward to measure the thermal accommodation coefficient at the interaction of the bulk material with gases at low temperatures [66]. However, the measurements of the accommodation coefficients of the NPs are non-trivial due to the very small sizes of these objects. By using the pulsed laser heating and the analysis of the LII signal decay rates (connected with the conductive-cooling rate) for a known primary-particle size, one should be able to infer the thermal accommodation coefficient, assuming that it is independent of particle-surface temperature. This is true for accurate LII modeling and if there are no other complicating factors (e.g. the influence on decay rate, particle aggregate size [67-74], particle morphology [74, 75], particle composition [76-79] and oxidation and annealing [2]).

The use of pulsed laser heating for determining the thermal energy accommodation coefficient is a convenient technique because it induces heat transfer with the surrounding gas and allows the subsequent cooling rate to be observed. The application of LII model for the interpretation of experimentally registered incandescence signals provides an opportunity to extract the thermal energy accommodation coefficient value by fitting the theoretical and experimental LII curves (if the particle size, density and heat capacity are assumed). A benefit of the measurements of thermal energy accommodation coefficient by LII is the uniform laser heating of the NPs, whereas the bath gas remains cold.

\subsection{The results of the accommodation coefficient measurements of soot using LII}

In an early work by Starke et al., the LII measurements of soot were performed in a shock tube reactor [80]. They found that the thermal accommodation coefficient $(\alpha)$ was equal to 1 at the interaction between the soot surface and argon molecules and that this fit the LII and transmission electron microscopy (TEM) results of particle sizing. However, the LII model used in this work was very simple and did not consider the possibility that properties could change with temperature, particle evaporation or real NP optical properties. Thus, the value of the thermal accommodation coefficient of the soot particles with argon reported in [80] could be a product of the authors' overestimation.

In the work of Snelling et al. [27], an $\alpha$ value of 0.37 was obtained from experiments conducted within a co-flow laminar ethylene diffusion flame. Additionally, in [31], the values of the thermal accommodation coefficient, which varied with soot temperature, were found to be in the range of 0.36-0.46. By fitting the normalized LII curves with the experimental curves until the best fit was attained, Krüger et al. [59] reported an $\alpha$ value of 0.38 for soot particles in a premixed laminar flame. The parameters of the particle size distribution were determined by scanning electron microscopy (SEM) measurements and by using the LII model. Kuhlmann et al. [68], based on the heat transfer model of McCoy and Cha, experimentally found that a value of $\alpha=0.25$ may be adequately employed to describe the "average" heat transfer behavior of a variety of black carbon samples in air under conditions relevant for LII. Analyzing the experimental data, based on the independently determined aggregate sizes, they obtained an extrapolated value of $\alpha=0.38-0.43$ for the idealized case of an isolated primary particle. In a study by Eremin and co-authors [81], from the comparison of LII and TEM data, the effective values of the thermal energy accommodation coefficient $\alpha$ in gas molecule collisions with a carbon NP surface were extracted by using the pulsed laser-heating method. These authors found that, for He atoms, the $\alpha$ value was equal to 0.1, whereas for other more heavy atoms and molecules (Ar, CO and $\left.\mathrm{C}_{3} \mathrm{O}_{2}\right)$, the $\alpha$ values were much higher $(0.44,0.44$ and 0.51 , respectively).

In a work by Daun et al. [82], the thermal accommodation coefficient was found from a regression of cooling decay time in LII measurements of laser-heated soot particles extracted from a flame into various gas atmospheres. The particle sizes and aggregation were measured by transmission electron microscopy. Their results indicates that the values of $\alpha$ were $0.05-0.5$ and that these depended on experimental conditions, including whether monatomic or polyatomic bath gases were used. Values below 0.1 appear to be associated with measurements of polyatomic gases that tend to thermally decompose at temperatures above $\sim 1000 \mathrm{~K}$. Maffi and co-authors [78] extracted information about the thermal accommodation coefficient by considering the gas/particle initial temperature obtained with thermocouple measurements in flame and by determining the soot particle diameter in previous TEM and extinction/scattering measurements. A larger variation in the value of $\alpha$ was observed, ranging from 0.22 for young soot and 0.34 for mature soot. This is likely due to a significant change in the height, both of the physical 


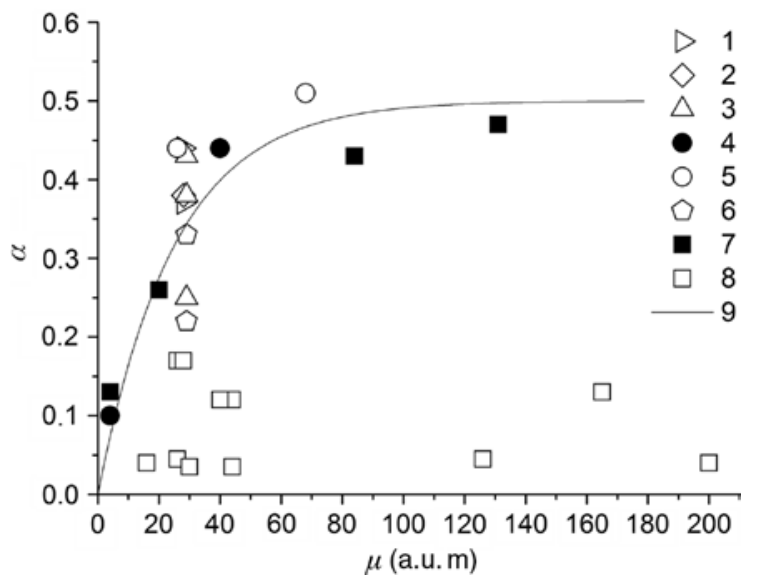

Figure 1: The measured values of the thermal accommodation coefficients of carbon NPs dependent on the molecular weight of bath gases. Closed symbols: data for the monoatomic gases, open symbols: data for the polyatomic gases. (1) data by Snelling et al. [27], (2) data by Krüger et al. [59], (3) data by Kuhlmann et al. [68], ( 4 and 5) data by Eremin et al. [81], (6) data by Maffi et al. [78], (7 and 8) data by Daun et al. [82], (9) best fit of monoatomic gas data by dumped exponential curve.

and chemical properties of soot particles and of the gas molecules present.

Daun and co-authors $[83,84]$ compared the values of the thermal accommodation coefficients extracted using various experiments in graphite/gas systems with molecular dynamics calculations results, concluding that reasonable agreement has been obtained. In Figure 1, the measured values of the thermal accommodation coefficients of carbon NPs as a function of the molecular weight of the bath gas are summarized and presented.

\subsection{The results of the accommodation coefficient measurements of the non-soot particles using LII}

Proposed measurement methods of the thermal accommodation coefficient of non-soot particles are scant. One of the earliest studies by Starke et al. [80] addressed the evaluation of LII signals from Fe NPs synthesized in the pyrolysis of $\mathrm{Fe}(\mathrm{CO})_{5}$ with argon in a shock tube. The thermal accommodation coefficient value $(\alpha=0.33)$ was estimated by the best fitting approach measured by TEM and calculated by LII Fe particle sizes. However, as in the case of soot particles, the results of the evaluation of thermal accommodation coefficient of Fe NPs in argon were overestimated.

The next measurements were performed with carbonencapsulated Fe NPs synthesized by the photolysis of ferrocene $[85,86]$. The particles were heated by a pulse excimer Ar-F laser at a wavelength of $193 \mathrm{~nm}$. The timeresolved spectroscopy made it possible to follow the cooling of the particles, and the dominant cooling processes could be identified by comparing the measured cooling rates with theoretically suggested data. The thermal accommodation coefficients for the Ar and Xe molecules during Fe NP collisions ranged from 0.19 to 0.2 and those from the He and hydrogen gases were found to be 0.096 and 0.044 , respectively. The question on what kind of materials are related to the heat transfer of the carbon-encapsulated Fe NPs with bath gases remains. For the carbon encapsulated NPs, carbon should be the surface material involved in the conduction heat transfer. However, as will be discussed below, these thermal accommodation coefficient values are correlated with data for Fe.

In a study by Eremin and co-authors [87], the measurements of the thermal accommodation coefficients of pure Fe NPs synthesized in the photolysis of $\mathrm{Fe}(\mathrm{CO})_{5}$ at room temperature were performed by pulsed laser heating using the common LII wavelength of $1064 \mathrm{~nm}$. By fitting the LII and TEM data, the values of the thermal accommodation coefficient of CO, argon and helium with Fe NPs were found to be $0.2,0.1$ and 0.01 , respectively. The value for argon is close to that reported in [26] $(\alpha=0.13)$. In [26], the Fe NP laser heating was performed in a hot wall flow reactor filled with argon and nitrogen as carrier gases. The synthesized Fe NPs by the pyrolysis of $\mathrm{Fe}(\mathrm{CO})_{5}$ were analyzed by TEM and LII. Based on the least square fit of the experimental LII decay curve and the calculated curve defined by the LII model, a thermal accommodation coefficient value was determined as $\alpha=0.13$ for both $\mathrm{N}_{2}$ and Ar.

In [43], a comparative analysis of the Fe NP sizes and thermal accommodation coefficients inferred from the LII data returned $\alpha$ values of $0.04(\mathrm{Fe} / \mathrm{He}), 0.14(\mathrm{Fe} / \mathrm{Ne}), 0.19$ (Fe/Ar), $0.08\left(\mathrm{Fe} / \mathrm{N}_{2}\right), 0.09$ (Fe/CO), $0.11\left(\mathrm{Fe} / \mathrm{N}_{2} \mathrm{O}\right)$ and 0.13 $\left(\mathrm{Fe} / \mathrm{CO}_{2}\right)$. The Fe NPs were synthesized in water and then aerosolized into various monatomic and polyatomic gases using a pneumatic atomizer. However, the NP sizes inferred from the ex situ (TEM and dynamic light scattering) techniques were inconclusive. Thus, the NP sizes were defined by LII together with $\alpha$, which resulted in additional uncertainty. In a newer work by Sipkens et al. [39], the same technique was applied. As in [43], the thermal accommodation coefficient values for the Fe and Mo nanoparticles were inferred from the LII data and resulted in $\alpha$ values of $0.24(\mathrm{Fe} / \mathrm{Ar}), 0.07\left(\mathrm{Fe} / \mathrm{N}_{2}\right), 0.12\left(\mathrm{Fe} / \mathrm{CO}_{2}\right), 0.05(\mathrm{Mo} / \mathrm{He}), 0.16$ (Mo/Ne), $0.24(\mathrm{Mo} / \mathrm{Ar}), 0.18\left(\mathrm{Mo} / \mathrm{N}_{2}\right)$ and $0.23\left(\mathrm{Mo} / \mathrm{CO}_{2}\right)$. The abovementioned thermal accommodation coefficient values determined for metal NPs are in a good agreement with the molecular dynamics simulation results reported 


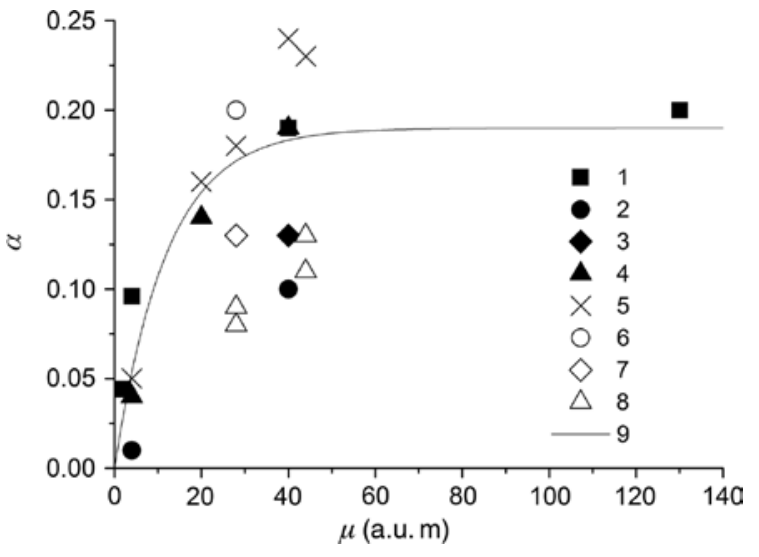

Figure 2: The measured values of the thermal accomodation coefficient in the conduction heat transfer of Fe and Mo NPs in dependence on molecular weight of bath gases. Closed symbols: data for the monoatomic gases. Open symbols: data for the polyatomic gases, (1) data by Elihn et al. and Landström et al. [85, 86], (2 and 6) data by Eremin et al. [87], ( 3 and 7) data by Kock et al. [26], (4 and 8) data by Sipkens et al. [43], (5) data for Mo NPs by Sipkens et al. [39], (9) best fit of monoatomic gas data by dumped exponential curve.

by Daun et al. in [88]. In Figure 2, the measured values of the thermal accommodation coefficients of metal nanoparticles as a function of the molecular weight of bath gas are summarized and presented.

\subsection{The variation of the thermal energy accommodation coefficient in terms of dependence on the bath gas type}

From the analysis of the data presented in Figures 1 and 2, it can be concluded that the values of the thermal accommodation coefficient of NPs range from 0.01 to 0.5. These values depend on the molecular weight and type of bath gas. For example, the values for both carbon and metal NPs are typically less in the case of polyatomic gases in comparison to those of monoatomic gases. Note that in the case of carbonaceous NPs, most measurements were performed in flames, where the bath gas was a complex composition of products of hydrocarbon combustion in air. These data are presented as open symbols in Figure 1 and correspond to the polyatomic gases with a molecular weight of nitrogen, which is the main component of the flame gases. For the bath gases, a dumped exponential curve is typically detected with an increase in molecular weight. The measured values of the thermal accommodation coefficient do not exceed 0.5 for carbonaceous NPs and 0.25 for metal NPs. In the experiments, the temperature of laser energized NPs were nearly the same, and the temperature of bath gases was varied from room temperature up to a flame temperature of $1200-1600 \mathrm{~K}$. The variation of the bath gas temperature and composition could account for the deviations seen in the data in Figure 1, which were obtained under the flame conditions at a molecular weight equal to 28. Data obtained in the monoatomic gases show a dumped exponential trend for both carbonaceous and metallic NPs, whereas the data obtained in polyatomic gases demonstrate an individual behavior independent of the bath gas molecular weight. Thus, the dependence of the thermal accommodation coefficient on the molecular weight of polyatomic gases should be additionally investigated at the same gas temperature. Nevertheless, as an initial approach, if any reliable data are absent, the obtained experimental data on the thermal accommodation coefficients (except data by Starke et al. [80]) could be used under different investigated conditions.

Dozens of articles are devoted to the uncertainty analysis of size distribution measurements using LII, but the uncertainty analyses of thermal accommodation coefficient determination have been carried out in [39, 43, 82]. A past study [82] has reported on the determination of the accommodation coefficient of soot in various gases from LII measurements most sensitive to perturbations in particle density, heat capacity and particle size. Uncertainties in these parameters $\pm 10 \%-20 \%$ result in $12 \%-24 \%$ uncertainty of accommodation coefficients; obtaining the summary of these parametric uncertainties results in about $\pm 50 \%$ uncertainty in the $\alpha$ values, which is largely responsible for the wide range of LIImeasured thermal accommodation coefficients reported in the literature. In [39], the evaluation of $\alpha$ uncertainty of $21 \%-44 \%$ has been presented for Fe and Ag NPs in Ar, $\mathrm{N}_{2}$ and $\mathrm{CO}_{2}$, and for Mo NPs in He, Ne, $\mathrm{Ar}, \mathrm{N}_{2}$ and $\mathrm{CO}_{2}$. In [43], the error of the experimental measurements of the thermal accommodation coefficient of Fe NPs in various gases has been evaluated as $14 \%$. Thus, the accuracy of the thermal accommodation coefficient determination is comparable with the accuracy of the LII sizing of NPs and could be evaluated as $15 \%-40 \%$. Determination in the thermal accommodation coefficient is most sensitive to perturbations in particle size. Thereby, for better accuracy of accommodation coefficient determination by LII, the independent method of particle sizing with minimal error is needed.

The aggregate shielding factor $0.75-0.92$ (in dependence on aggregate size, up to 100 particles per aggregate) at the free molecular conductive heat transfer of soot NPs with surrounding gas has been evaluated in [84], revealing a 3\%-4\% error in the accommodation coefficient determination using the LII model. 
The further directions of the investigation of the thermal accommodation coefficients of NPs by pulsed laser heating include the study of the influence of gas and particle temperature on measurement results, variation of the particle and gas types as well as the development of alternative particle-sizing techniques.

\section{The determination of the NP evaporation temperature}

\subsection{The evaporation conditions of the NPs under pulsed laser heating}

The investigation of phase transitions in nanoscale materials is of great importance for modern condensed matter physics. One type of phase transition is the sublimation or evaporation of the NP material. Here, we focus on the sublimation/evaporation induced by pulsed laser heating. The interaction of condensed particles with pulsed laser radiation is a complex process that depends on many factors, among which the principal factors are the laser fluence and pulse duration. With long laser pulses and low fluence, the laser radiation slowly heats the solid up to an evaporation/sublimation threshold. If the peak power density is lower than $1 \mathrm{MW} / \mathrm{cm}^{2}\left(0.01 \mathrm{~J} / \mathrm{cm}^{2}\right.$ for $10 \mathrm{~ns}$ laser pulse), the energy distribution of the species leaving the surface is no different from that of the equilibrium case [89]. The sublimation and evaporation are zero-order processes (i.e. the rate of mass loss of a sample under the isothermal conditions due to evaporation should be a time constant value as long as its free surface area does not change). However, the isothermal conditions during laser heating are not fulfilled due to the very large temperature gradient between the surface and the cold surrounding gas. The equilibrium exists only within the Knudsen layer, with a thickness of the order of mean free path of vapor molecules [90]. This gradient causes the rapid expansion of the vapor phase away from a surface and does not allow the reverse vapor condensation, which otherwise occurs in the equilibrium conditions. This leads to the corrections of the equilibrium formula for vapor pressure, taking into account the efficiency of the reversal condensation process [91].

At the sufficiently high laser intensity, the majority, if not all, of the materials removed from the solid will become ionized. The plasma effects start to dominate when the peak power density exceeds $1 \mathrm{GW} / \mathrm{cm}^{2}$ [92]. Using the pico- and femtosecond lasers, the laser power increases at 3 and 6 orders of magnitude, respectively, opposite to the same pulse of the ns laser. A power of the ns laser of $1 \mathrm{MW} / \mathrm{cm}^{2}$ becomes $1 \mathrm{GW} / \mathrm{cm}^{2}$ and $1 \mathrm{TW} / \mathrm{cm}^{2}$ using the pico- and femtosecond lasers at the same energy per pulse. Such a power laser interaction with NPs could even be a source of X-ray emission [93].

The intermediate laser power $\left(1 \mathrm{MW} / \mathrm{cm}^{2}-1 \mathrm{GW} / \mathrm{cm}^{2}\right.$, $0.01-10 \mathrm{~J} / \mathrm{cm}^{2}$ for $10 \mathrm{~ns}$ lasers) is the most practical for the pulsed laser-material interactions. In this range of laser fluences, some deviations from the equilibrium conditions might exist. This laser power $\left(0.01-10 \mathrm{~J} / \mathrm{cm}^{2}\right.$ for $10 \mathrm{~ns}$ lasers) results in hot atoms and clusters appearing at the laser light interaction with NPs. Murakami et al. [94] observed the Mo atom emission lines (380, 420 and $540 \mathrm{~nm}$ ) from Mo NPs heated by the Yag laser pulse with the laser fluence $0.34 \mathrm{~J} / \mathrm{cm}^{2}$. All the emission lines of the Mo atoms disappeared within $350 \mathrm{~ns}$ after the pulsed irradiation at $1064 \mathrm{~nm}$. The photochemical interference of the laser light with the flame-generated soot was observed in [95]. At fluences below $0.2 \mathrm{~J} / \mathrm{cm}^{2}$ at $532 \mathrm{~nm}$ excitation, the measured spectra demonstrate the broadband featureless emission characteristics of laser-induced incandescence. In comparison, at higher fluences, the spectra show sharp features attributable to the $\mathrm{C}_{2}$ Swan band emission, the $\mathrm{C}_{3}$ Swings band emission and other species. At higher laser fluencies (up to $3.5 \mathrm{~J} / \mathrm{cm}^{2}$ ), the spectra become a series of features instead of the broadband emission. The feature emission in the UV that are visible from the electronically excited atoms and clusters can be a result of photochemical interferences of laser light with the NPs. The total elimination of the NP-phase matter by laser pulse due to the excited to plasma state occurs at laser fluences of $10-35 \mathrm{~J} / \mathrm{cm}^{2}$, as also observed in $[96,97]$ for the $\mathrm{TiO}_{2}$ NPs.

During the NP evaporation with pulse laser fluences higher than $0.3 \mathrm{~J} / \mathrm{cm}^{2}$, the high translational energies and the narrower translational energy distributions of the vapor molecules, which are more characteristic for a supersonic expansion, could take place [2]. Moreover, the photodesorption and evaporation peculiarities of the annealed particles [2] can occur at high laser fluences. As a result of the higher-power pulsed laser radiation (over $100 \mathrm{MW} / \mathrm{cm}^{2}$ or 1 $\mathrm{J} / \mathrm{cm}^{2}$ for $10 \mathrm{~ns}$ laser pulses) the ablation or phase explosion could be considered as important mass loss mechanisms [98]. Indeed, when analyzing LII measurements from silica NPs with mean size of $25 \mathrm{~nm}$, the authors of a past study [99] proposed that, at fluences above $0.5 \mathrm{~J} / \mathrm{cm}^{2}$, an inverse Bremsstrahlung heating due to the strong coupling of the laser and the plasma can significantly contribute to the measured signal intensity. Thus, for the investigation of the NP phase transition using LII, relatively low laser fluences (less than $0.5 \mathrm{~J} / \mathrm{cm}^{2}$ ) should be applied. 
When the laser fluence increases, the particle temperature reaches a maximum due to the evaporation or sublimation of the particle material during pulsed laser heating. In the LII measurements, the peak temperature is saturated when the sublimation/evaporation is reached. This behavior was first observed in 1977 by Eckbreth [55]. The evidence of evaporation processes induced by laser heating provides the measurements of laser light extinction $[56,61]$ or laser light scattering $[57,58]$. The plateau in the peak temperature with laser fluence rises and the gradual decrease of the volume fraction of condensed phase dependent on the laser fluence allow indicates that the phase transition has occurred. In this case, the peak temperature on the plateau could be attributed to the temperature of the phase transition. The reliable information on peak temperature could be obtained at low laser fluences (not essentially higher than evaporation/sublimation threshold).

Using Equation (11), the value of temperature $\left(T_{\max }\right)$ at peak-LII signals can be determined from the ratio of peak intensities of the LII signals on two wavelengths. The uncertainty of the temperature measurement of laserheated NPs by LII was investigated in [100-104]. This shall be discussed below.

\subsection{The measurements of the peak temperature of laser-heated carbonaceous NPs}

The existing experimental measurements of the peak particle temperature should be carefully revised in connection with the applied laser fluence. Most of the data deal with the soot particles. As was pointed out for flame soot particles, very small deviations in the LII spectra from the Planck curve are observed at laser fluences higher $0.3 \mathrm{~J} / \mathrm{cm}^{2}$, and essential deviations are observed at $0.5-1.5 \mathrm{~J} / \mathrm{cm}^{2}$ [101]. Thus, at moderate laser fluences $\left(0.1-0.5 \mathrm{~J} / \mathrm{cm}^{2}\right)$ the LII signal is caused by the usual thermodynamic reasons, without considering the plasma formation or photoluminescence emission lines of bounds from evaporating atoms and molecules. The peak particle temperature data in the LII measurements are summarized in Table 3.

The first measurements of the soot temperatures at peak irradiance (based on two-wavelength pyrometry) were reported by Eckbreth [55], and temperatures between $4000 \mathrm{~K}$ and $5000 \mathrm{~K}$ were observed in that study. Notably, at fluences less than $0.5 \mathrm{~J} / \mathrm{cm}^{2}$, the peak temperature does not exceed $4000 \mathrm{~K}$, whereas the peak temperature exceeds $4000 \mathrm{~K}$ at laser fluences greater than $0.5 \mathrm{~J} / \mathrm{cm}^{2}$, where the plasma effects are essential.

The measured peak temperatures of carbon NPs synthesized in the pyrolysis of $\mathrm{C}_{2} \mathrm{H}_{2}$ presented in [61], $3100-3800 \mathrm{~K}$, are less than those of the graphite sublimation temperature of $3900 \mathrm{~K}$ [110], and also below those obtained by LII measurements of soot, as reported in the literature. The values of $T_{\max }$ reported in [30, 32, 105, $106,108,111]$ and measured in flames at laser fluences higher than $0.1 \mathrm{~J} / \mathrm{cm}^{2}$ are within a range of $3700-4400 \mathrm{~K}$. However, in a diesel engine, the values of soot peak temperature measured by two-color techniques were found to be in the range of $2000-4000 \mathrm{~K}$ at the laser fluence of $0.25 \mathrm{~J} / \mathrm{cm}^{2}$ [107]. Such a large scattering of the experimental data can be explained by pulse-to-pulse fluctuation in laser energy and an unpredictable value of attenuation

Table 3: The soot particle peak temperatures measured by pulsed laser heating.

\begin{tabular}{llll}
\hline $\mathbf{N}$ & Conditions & $T(\mathbf{K})$ & References \\
\hline 1 & Propane diffusion flame & 4100 at $<0.5 \mathrm{~J} / \mathrm{cm}^{2}$ & Eckbreth [55] \\
& & $4100-5000$ at $>0.5 \mathrm{~J} / \mathrm{cm}^{2}$ & \\
2 & Ethylene diffusion flame & $4250-4500$ at $0.8 \mathrm{~J} / \mathrm{cm}^{2}$ & Schraml et al. [105] \\
3 & Premixed acetylene flame & $3500-4200$ at $0.1-0.74 \mathrm{~J} / \mathrm{cm}^{2}$ & Lehre et al. [106] \\
4 & Ethylene diffusion flame & $4000 \pm 100$ at $0.15-0.7 \mathrm{~J} / \mathrm{cm}^{2}$ & De luliis et al. [32] \\
5 & Diesel engine & $2000-4000$ at $0.25 \mathrm{~J} / \mathrm{cm}^{2}$ & Bougie et al. [107] \\
6 & Isooctane diffusion flame & $4035 \pm 200$ at $0.15 \mathrm{~J} / \mathrm{cm}^{2}$ & Boiarciuc et al. [111] \\
7 & Ethylene diffusion flame & $3500-4500$ at $0.52-1.69 \mathrm{~J} / \mathrm{cm}^{2}$ & Snelling et al. [31] \\
8 & Ethylene diffusion flame & 4500 at $0.2 \mathrm{~J} / \mathrm{cm}^{2}$ & Michelsen et al. [30] \\
9 & Ethylene premixed flame & 4100 at $0.5-0.57 \mathrm{~J} / \mathrm{cm}^{2}$ & Maffi et al. [78] \\
10 & Premixed ethylene/air flame, elastic light & $3560-3900 \mathrm{at} 0.16-0.27 \mathrm{~J} / \mathrm{cm}^{2}$ & Oloffson et al. [108] \\
11 & scattering measurements of soot sublimation & & Goulay et al. [109] \\
12 & Ethylene premixed flame & 4400 at $0.3 \mathrm{~J} / \mathrm{cm}^{2}$ & Eremin et al. [61] \\
& Shock tube soot formation in acetylene pyrolysis, & $3100-3800$ at $0.15-0.45 \mathrm{~J} / \mathrm{cm}^{2}$ & \\
\hline
\end{tabular}


between the site, where the laser beam enters the diesel cylinder and the site, where the soot probe is located. In [105], the temperature and heat of vaporization of soot ( $3930 \mathrm{~K}$ and $7.5 \times 10^{5} \mathrm{~J} / \mathrm{mol}$ ), which govern the energy and mass loss at high temperatures, were obtained by measurements of the maximum particle temperature for various laser irradiances at a peak temperature of $4200 \mathrm{~K}$.

Other soot peak particle temperature data are presented in Table 3, which shows values between 3500 and $4500 \mathrm{~K}$. At high laser fluences $\left(>0.3-0.5 \mathrm{~J} / \mathrm{cm}^{2}\right)$ the peak temperature reaches $4500 \mathrm{~K}$. At moderate fluences $\left(<0.3 \mathrm{~J} / \mathrm{cm}^{2}\right)$, the peak temperature does not exceed $4000 \mathrm{~K}$ (except as reported in the works by Michelsen et al. [30] and Goulay et al. [109]). Goulay et al. [109] have explained the high values of peak temperature (e.g. $4500 \mathrm{~K}$ ) of soot by reaching the sublimation temperature of $\mathrm{C}_{2}-4456 \mathrm{~K}$, suggesting little or no superheating. The peak temperature elevation at fluences higher than $0.5 \mathrm{~J} / \mathrm{cm}^{2}$ is explained by fluorescence interferences from the molecules present in the flame.

Due to the uncertainty of the wavelength dependence of $E(m)$, Schraml et al. [105] evaluated the systematic deviation in peak temperature as $200 \mathrm{~K}$. In [31], it has been reported that once the evaporative regime is reached, the model prediction of post-laser pulse soot temperatures is in very poor agreement with the data on experimental temperatures; in this case, the obtained temperature can be as much as $400 \mathrm{~K}$ higher than the model prediction, thus indicating deficiencies in the present models of vaporization. Thus, the large discrepancy between the model prediction and experimental data in the evaporative regime is attributable to the gas dynamics effect or the reformation of carbon particles. Furthermore, in [105], the effects of temporal and spatial energy distribution in the laser beam were analyzed. The authors of that work found that these roughly cancel each other out, and the small net effects that remain have been neglected.

Analyzing the data reported to date, it is possible to conclude that, at moderate laser fluences (less than $0.3-0.5 \mathrm{~J} / \mathrm{cm}^{2}$ at $1064 \mathrm{~nm}$ excitation), the plasma effects and superheating are negligible effects. The measured values of soot peak temperatures deviate in the range of $3100-4500 \mathrm{~K}$. We suppose that this deviation is caused by differences in structures and compositions of NPs formed under different conditions resulted in the deviation of the NP properties. For example, Schraml et al. [105] observed the influence of soot NP size on calculated peak temperature. They found that for particles $25 \mathrm{~nm}$ in size, the peak temperature was $4150 \mathrm{~K}$ and increased up to $4300 \mathrm{~K}$ for particles with sizes $48 \mathrm{~nm}$. Further, in [61], the experimental data on the peak temperatures of carbonaceous
NP has been reported to depend on particle size and formation (pyrolysis) temperature. Moreover, under flame conditions, the inferred temperatures of laser-heated soot particles are often higher than the equilibrium sublimation temperature of $\sim 4140 \mathrm{~K}$, at which $\mathrm{C}_{3}$ sublimes $\left(\mathrm{C}_{3}\right.$ sublimation temperature $4136 \mathrm{~K}$ at atmospheric pressure), and particles sometimes appear to reach temperatures of $\sim 4460 \mathrm{~K}$, at which $\mathrm{C}_{2}$ sublimes [55, 98, 109].

Finally, the easiest explanation of the observed fluence curve plateau is a phase transition connected with the particle sublimation/evaporation. Additional evidence of sublimation/evaporation features a sharp decrease in the volume fraction of the condensed phase in the moment of laser pulse (observed by laser light extinction or laser light scattering using the coaxial extinction measurements simultaneously with the registration of the LII signals), which increases as the fluence rises [56-59, $61,108]$.

\subsection{The results of measurements of peak temperature of laser heated non- carbonaceous particles}

The peak temperature of metal NPs has been measured in a few past works and presented in Table 4. In [26], Fe NPs (18-29 nm in size) were synthesized in a flow reactor and heated by pulse laser for the LII size measurements. With a laser fluence of $0.32 \mathrm{~J} / \mathrm{cm}^{2}$, the peak temperature measured by two-color pyrometry was equal to $2850 \mathrm{~K}$. At the lowest fluence of $0.19 \mathrm{~J} / \mathrm{cm}^{2}$, the lowest temperature of about $2600 \mathrm{~K}$ was registered. With increasing laser fluence, the particle peak temperatures increased but remained below $3150 \mathrm{~K}$, which was close to the bulk Fe boiling temperature of around $3100 \mathrm{~K}$ [112]. Eremin et al. [61] measured the peak temperature of the laser-heated Fe particles of the sizes $\sim 3 \mathrm{~nm}$ for the different surrounding conditions. Similar to carbon particles, the peak particle temperature of the laser-heated Fe particles did not change at laser fluences greater than $0.1 \mathrm{~J} / \mathrm{cm}^{2}$, which was explained as a phase transition. The peak temperature of the laserheated Fe NPs varied from 2100 to $2600 \mathrm{~K}$ depending on the type and pressure of bath gas, which was below the boiling temperature of $\mathrm{Fe}$ (around $3100 \mathrm{~K}$ ). The maximal peak particle temperatures for Fe NPs in 1 bar of argon, 0.1 bar of argon and 1 bar of helium were found to be $\sim 2600 \mathrm{~K}$, $\sim 2150 \mathrm{~K}$ and $\sim 2300 \mathrm{~K}$, respectively. This means that the NP evaporation process depends on the pressure and type of ambient gas, as well as on the NP size.

In [94], Mo NPs were studied by LII. The incandescence spectra induced by pulsed laser irradiation at 
Table 4: The non-soot particle peak temperatures measured by pulsed laser heating.

\begin{tabular}{|c|c|c|c|}
\hline $\mathbf{N}$ & Conditions & $T(\mathrm{~K})$ & References \\
\hline 1 & Fe NPs in heated flow reactor & 2850 at $0.32 \mathrm{~J} / \mathrm{cm}^{2}$ & Kock et al. [26] \\
\hline 2 & $\begin{array}{l}\text { Fe NPs in photolysis reactor, extinction measurements of NP } \\
\text { evaporation }\end{array}$ & $2100-2600$ at $0.05-0.67 \mathrm{~J} / \mathrm{cm}^{2}$ & Eremin et al. [61] \\
\hline 3 & $40 \mathrm{~nm}$ commercial Fe NPs at room temperature & $3100-3400$ at $0.2-0.3 \mathrm{~J} / \mathrm{cm}^{2}$ & Sipkens et al. [39] \\
\hline 4 & Mo NPs in photolysis reactor & $3500-4000$ at $0.13 \mathrm{~J} / \mathrm{cm}^{2}$ & Murakami et al. [94] \\
\hline 5 & $40 \mathrm{~nm}$ commercial Mo NPs at room temperature & 2800 at $0.2-0.3 \mathrm{~J} / \mathrm{cm}^{2}$ & Sipkens et al. [39] \\
\hline 6 & Mo NPs in photolysis reactor & 3900 at $0.3-0.6 \mathrm{~J} / \mathrm{cm}^{2}$ & Eremin et al. [114] \\
\hline 7 & $70 \mathrm{~nm}$ commercial Ag NPs at room temperature & 2800 at $0.2-0.3 \mathrm{~J} / \mathrm{cm}^{2}$ & Sipkens et al. [39] \\
\hline 8 & Silica NPs $20-25 \mathrm{~nm}$ in size in microwave plasma reactor & $3000-4500$ at $0.1-1 \mathrm{~J} / \mathrm{cm}^{2}$ & Menser et al. [99] \\
\hline 9 & Carbon-encapsulated Fe NPs in photolysis reactor & 3100 at $0.11 \mathrm{~J} / \mathrm{cm}^{2}$ & Landström et al. [86] \\
\hline 10 & $\begin{array}{l}\text { Carbon-encapsulated Fe NPs in photolysis reactor, extinction } \\
\text { measurements of NP evaporation }\end{array}$ & $2700-2900$ at $0.3-1 \mathrm{~J} / \mathrm{cm}^{2}$ & Eremin et al. [115] \\
\hline 11 & $\begin{array}{l}\text { Carbon-encapsulated Fe NPs in shock tube reactor, extinction } \\
\text { measurements of NP evaporation }\end{array}$ & $2770-2850$ at $0.1-0.7 \mathrm{~J} / \mathrm{cm}^{2}$ & Eremin et al. [117] \\
\hline
\end{tabular}

$1064 \mathrm{~nm}$ with high fluences resulted in a peak particle temperature value of $5300 \mathrm{~K}$ and atomic emissions of Mo atoms. This exceeds the boiling temperature of bulk Mo (4983 K [113]). The LII signals were registered by photomultiplier on $400 \mathrm{~nm}$ and by fast ICCD camera. The temperature evolution was extracted by fitting spectra resolved LII with the Planck curve. However, the influence of the wavelength dependence of $E(m)$ was not discussed. Eremin and Gurentsov [114] synthesized 9-10 nm Mo NPs in the photolysis of $\mathrm{Mo}(\mathrm{CO})_{6}$ similar to the authors of [94]. In [114], two-color LII on wavelengths 400 and $600 \mathrm{~nm}$ was applied to conduct laser-heated NP temperature determination. In this work, the spectral variation of $E(m)$ was neglected because of the absence of experimental knowledge about wavelength dependence of Mo NP optical properties. With the increase in laser fluence, the peak temperature value also increased up to a temperature of about $3900 \mathrm{~K}$ and, when starting the fluences at greater than $\sim 0.3 \mathrm{~J} / \mathrm{cm}^{2}$; the peak temperature value did not change. The value of the peak particle temperature of about $3900 \mathrm{~K}$ at high laser fluences was attributed to the value of the particle evaporation temperature. Notably, the peak particle temperature was essentially lower than the boiling temperature of bulk Mo (4983 K), even at high fluences. This finding might indicate the deviation of NP properties from the bulk Mo. In [39], 40-nm Mo NPs were examined by LII. The peak temperatures of the Mo NPs increased approximately linearly with increasing laser fluence of up to $0.2-$ $0.3 \mathrm{~J} / \mathrm{cm}^{2}$ and returned a value of $2800 \mathrm{~K}$. The inspection of the pyrometric temperature decay for Mo NPs reveals a super-exponential decay in the effective temperature that lasts for approximately $400 \mathrm{~ns}$ after the laser pulse, which cannot be explained by the free molecular heat transfer cooling. Consequently, in this study, the low value of peak particle temperature and behavior of temperature decay after laser heating remains unexplained.

In [99], silica NPs (20-25 $\mathrm{nm}$ in size) were synthesized and examined by LII. At prompt LII detection, the peak temperature with laser fluence increase returned values of $4500 \mathrm{~K}$, which was much more than the boiling temperature of bulk silicon $3000 \mathrm{~K}$. At a detection time of 50-100 ns after the laser pulse, the peak temperature as a function of laser fluence plateaued at $3000 \mathrm{~K}$. The authors explained such a peak temperature behavior by superheating of NPs in the time of laser action. However, another explanation could be a nonthermal emission under high laser fluences.

In [39], Ag NPs (70 $\mathrm{nm}$ in size) were examined by LII. The peak temperatures of Ag NPs remained nearly constant with increasing laser fluence at $2800 \mathrm{~K}$, which was higher than the boiling point of bulk Ag $2466 \mathrm{~K}$. The authors suggested that the Ag NPs were superheated and that the additional laser heating was roughly balanced with an increased evaporation rate. In their interpretation, the measured peak temperature value of laser-heated NPs strongly depended on the spectral incandescence data. Using an $E(m)_{r}=2.67$ (obtained from Drude theory) value in a maximum peak temperature $\sim 200 \mathrm{~K}$ above the boiling temperature, while using a value of $E(m)_{r}=1$ resulted in a peak temperature of $\sim 3600 \mathrm{~K}$.

One further attempt at measuring the peak temperature was made using carbon-encapsulated Fe NPs (CEINs). In [86], the CEINs (8 nm Fe core and $18 \mathrm{~nm}$ total diameter) were synthesized by the photolytic decomposition of ferrocene. The results indicated that the peak temperature of laser-heated CEINs increased with increasing laser fluence. The minimum peak temperature was found to be $2000 \mathrm{~K}$ at a laser fluence of $0.07 \mathrm{~J} / \mathrm{cm}^{2}$. A saturation 
effect was also observed above $0.11 \mathrm{~J} / \mathrm{cm}^{2}$, with a saturation temperature of $3100 \mathrm{~K}$, which was very close to the boiling point of Fe. The authors supposed that the intense evaporation of $\mathrm{Fe}$ atoms led to the temperature stabilization of the particles. At laser fluences greater than $0.1 \mathrm{~J} / \mathrm{cm}^{2}$, the evaporation can be so strong that it can lead to a significant amount of Fe loss from the core of the NPs. Eremin et al. [115] measured the peak temperature of CEINs, synthesized by the photolytic decomposition of $\mathrm{Fe}(\mathrm{CO})_{5}$ in the mixture with acetylene, as a function of the laser fluence. Under the framework of the LII model, they assumed that in the Rayleigh approximation all the particle materials heat up to the close temperatures due to the fast energy exchange between Fe core and carbon shell. The measured in [115] value of peak particle temperature by the two color technique was in the range $2500-2900 \mathrm{~K}$ in dependence on the particle formation conditions. At higher fluences, temperatures also fall within this range, suggesting that the temperature corresponds to the $\mathrm{Fe}$ core due to the boiling temperature of bulk Fe is $3100 \mathrm{~K}$. Thus, the fast conductive heat exchange between carbon shell and Fe core could be the case. Using the two-color temperature measurements, it becomes necessary to know only the ratio of $E(m)$ on the measurement wavelengths. For soot particles, this dependence is weak [104]. The extinction measurements with Fe NPs at various temperatures at different wavelengths did not show any difference of $E(m)$ with wavelength [116]. Thus, the ratio of the values of $E(m)$ for 772 and $450 \mathrm{~nm}$ equal to 1 was used in [115] at peak temperature measurements. The application of the ratio of $E(m)_{772} / E(m)_{450}=0.56$ (at diagnostic wavelengths 450 and $772 \mathrm{~nm}$ ) from the study by Sipkens et al. [43] for two-color measurements resulted in the peak temperature decrease by $9 \%-12 \%$ in dependence on the experimental conditions. In [115], it was found that the peak temperatures do not exceed $2900 \mathrm{~K}$ with the increase in laser fluence, which is lower than bulk Fe boiling temperature $(3100 \mathrm{~K})$. The flattening of the peak temperature dependence on the laser fluence means that a phase transition with heat absorption occurs. This phase transition at such a low temperature could be the Fe core evaporation under an amorphous carbon shell, similar to [86]. The carbon material sublimation from the NP surface shell is unlikely at the temperatures below $3500 \mathrm{~K}$. The extinction measurements of the volume fraction of the condensed phase during laser heating showed an essential drop due to a decrease of the volume of the condensed phase. Such a drop reflects the particle evaporation process.

In [117], the peak temperatures of CEINs, formed in the shock wave pyrolysis of the mixtures of $0.25 \%$
$\mathrm{C}_{6} \mathrm{H}_{6}+0.25 \% \mathrm{Fe}(\mathrm{CO})_{5}$ in $\mathrm{Ar}$ and $0.5 \% \mathrm{C}_{2} \mathrm{H}_{2}+0.25 \% \mathrm{Fe}(\mathrm{CO})_{5}$ in $\mathrm{Ar}$, were also measured by two-color pyrometry. In both the investigated mixtures, the peak particle temperature of CRINs was stable, despite the fact that the laser fluence rise and that the mean peak temperature values were found to be 2852 and $2770 \mathrm{~K}$, which were lower than the bulk Fe boiling temperature ( $3100 \mathrm{~K}$ ). The plateau of peak temperature as a function of laser fluence indicates that the phase transition with heat absorption has occurred.

\subsection{The uncertainties in measuring the peak temperatures of the laser-heated NPs}

The main uncertainty in peak temperature measurements come from the application of high laser fluences $\left(>0.5 \mathrm{~J} / \mathrm{cm}^{2}\right)$, and using a laser wavelength shorter than $1064 \mathrm{~nm}$ resulted in plasma formation, super heating, excited atoms and cluster light emission as well as the photochemical interference of laser light with NPs [9497]. If the fluence is not high for plasma and excited species formation, the accuracy determined by $E(m)$ varied with wavelength. In [39], the influence of $E(m)$ ratio $E(m)_{r}=E(m)_{442 \mathrm{~nm}} / E(m)_{716 \mathrm{~nm}}$ on peak temperature measurement was investigated for metal NPs. In the case of the two-color measurements of the peak temperature of the laser-heated Fe, Ag and Mo NPs dependent on the laser fluence, the peak temperature deviations (on the fluence curve plateau) were found to be $400 \mathrm{~K}$ at the $E(m)_{r}$ varied in the range of $1-1.85$ for Fe NPs, $500 \mathrm{~K}$ at $E(m)_{r}$ varied in the range of 1.5-2.86 for Ag NPs and $500 \mathrm{~K}$ at $E(m)_{r}$ varied in the range of 1-1.89 for Mo NPs. In [39], the reliable values of $E(m)_{r}$ was established as 1.1 for Fe NPs supported on previous LII studies, the value $E(m)_{r}=2.67$ was established for Ag NPs obtained from Drude theory results, and the value $E(m)_{r}=1.59$ derived from the ellipsometry measurements on polished Mo. Thus, the error of peak temperature determination due to the uncertainty of the $E(m)_{r}$ value could be estimated as $\pm 250 \mathrm{~K}$.

The current uncertainties in the peak temperature measurements of carbonaceous NPs by the pulsed laserheating method reached $\sim 200 \mathrm{~K}$ for mature soot [101, 103] and were even higher for less mature soot [103]. The higher values of the surrounding temperature during the particle growth could result in different particle properties (mainly related to the particle structure, which becomes more graphitized at elevated temperatures [118]). This leads to the distinction in the particle evaporation process under laser heating, either due to changes in the evaporation enthalpy or the composition of the evaporated species or due to an increase of the vapor 
pressure and decrease the evaporation temperature with a decrease of particle size, similar to that observed for metal NPs [119].

The next point is the superheating of the NPs related to the temporal resolution of the signal detection and to the interaction of heating and cooling within a ns pulse. Sipkens et al. [39] had postulated that the peak temperature on the plateau of fluence curve should be higher than the boiling point due to the fact that laser energy is added to the NP faster than it can be removed through evaporation, which is limited by the Clausius-Clapeyron equation. Consequently, the excess of laser energy during the laser pulse causes a superheating of the NPs. However, superheating is not an error of measurement, but a probable physical effect which is absent in the formula of the twocolor pyrometer (11). Of course, the temporal resolution of the signal detection could influence the error of peak temperature measurements as pointed out by Menser et al. [99], who used the prompt and delayed LII spectra resolved measurements of silica NPs. The large difference in values of peak temperature just after the evaporation threshold $400 \mathrm{~K}$ was registered between prompt (streak star ICCD time resolution $1 \mathrm{ps)}$ and 50-100 ns delayed measurements. The detectors in the LII measurements usually have a time resolution less than $1 \mathrm{~ns}$ and, consequently, can register superheating if it exists. One can conclude that the registration of the NP superheating depends on the chosen wavelength dependence of $E(m)$. The authors of [39] stated that the peak temperature must be higher than the boiling temperature of the particle material and had supported their choice of wavelength dependence of $E(m)$ by this statement (see discussion about Fe NP peak temperature in [39]). However, for NPs, it would be reasonable to suppose that the phase transition temperature is lower than that for the bulk material [119-130].

The real value of the $E(m)$ ratio could be determined in the same experiment using two-color LII measurements on two excitation laser wavelengths (532 and $1064 \mathrm{~nm}$ ), as was done in [62]. The measured $E(m)$ ratio on the two laser wavelengths could be adapted for the $E(m)$ ratio determination on the wavelengths used for the LII registration.

One of the additional uncertainties of the two-color temperature measurements has been pointed out in [120]. When the photo-multiplayer tube (PMT) was used for the pyrometric temperature measurements, even small deviations from the linear detector response can lead to significant errors. The reasons for the non-linearity observed in the PMT measurement are summarized, and the strategies to identify nonlinear PMT operation in LII are outlined. A measured linearity deviation of up to $10 \%$ could bias the temperature determination by several hundred Kelvin. In [120], the guidelines are given for the design and the operation of LII set-ups, which allow users to identify and prevent errors.

\subsection{The future directions of investigations on NP properties}

It should be noted that there are numerous types of NPs. The typically mentioned soot particles are the group of carbonaceous NPs formed in the combustion processes. The properties of soot from the author's point of view are not the same for all types of soot particles. This statement is supported by the variation of data of $E(m)$ for soot summarized in [30, 104], where one can see an essential variation of $E(m)$ for flame soot formed in various conditions. Similarly, the different types of carbon black (produced at different conditions) have different standard properties, such as tinting strength, electrical conductivity and dispersion in liquids caused by the differences in particle size, shape and crystallinity. Thus, the collection of data on the arbitrary NP properties and their analyses of the dependence on particle size, composition and formation conditions are topics worthy of future investigations.

The value of the sublimation/evaporation temperature is an important thermodynamic property of the material. The evaporation of the NPs is predicted to be size-dependent and such knowledge is essential for their applications at higher temperatures. In addition, the sublimation/evaporation temperature variation of the NPs could be influenced by the variation in crystalline structure, shape and presence of impurities. It should be noted that the thermodynamic properties of NPs could differ from the properties of a bulk material due to the size effect. There is much evidence of a change of various NP properties with changing size, especially in the range from 1-2 to $10-20 \mathrm{~nm}$. Multiple calculations have predicted that the melting points of various NPs are dependent on size [121-123]. Moreover, the enhanced heat capacity of small NPs has been observed [124]. The size-dependence of the NP properties differs greatly relative to those of the bulk material [125-130]. In [125], it has been reported that a universal equation exists, which describes the dependences of various thermodynamic properties of metal NPs on their size. If one of the thermodynamic properties of NPs is known, the other properties could be determined from the ratio of this value to the corresponding bulk thermodynamics property. Using the universal relations from $[125,126]$, the experimental data on the size dependence 
of carbonaceous NP sublimation temperature were analyzed in [131]. The existence of a value of surface tension of the NPs much higher than that for graphite was supposed. Furthermore, the onset sublimation/evaporation temperature (before plateau in fluence curve) could also be analyzed for the investigation of the NPs' thermodynamic properties [125, 129]. Future investigations on the size dependence of the evaporation temperature of various NPs could shed light on the size-dependence of their thermodynamic properties. Separate investigations should also be devoted to studying the surrounding conditions (e.g. pressure, temperature and gas composition) that influence NP evaporation temperature, first observed in [61].

Notably, the uncertainty analysis of particle sizing or particle volume fraction determination by LII is similar to the determination of NP properties. Analyzing the uncertainties of particle size determination using LII was presented in the LII literature by Will et al. [132], Starke et al. [80], Eremin et al. [33] and Sipkens et al. [39], among other works. The particle volume fraction and pyrometric temperature measurements were presented in $[133,134]$. These analyses usually include probable uncertainty in heat capacity, density, surrounding temperature and pressure, heat of vaporization, refractive index function and their wavelength dependence on the uncertainty of the measured value. The uncertainties of $E(m)$ value determination were observed in [27], in which the value was linked to the pyrometric temperature measurements and with the uncertainties of NPs' heat capacity and density. The uncertainties of determining the accommodation coefficient were also discussed by Sipkens et al. [39]. The uncertainties of determining the pyrometric temperature were presented in $[39,99]$, in which the authors linked the $E(m)$ wavelength dependence to the changing $E(m)$ under extreme laser heating.

However, to achieve progress in the analysis of the uncertainty determination of the LII and NP properties, in the author's opinion, it is necessary to use the Bayesian method, which could provide the determination of several independent parameters from the fitting of LII signal with theoretical curve. However, the discussion of this idea is beyond the scope of this review because this topic demands separate consideration. The descriptions and examples of the application of the Bayesian technique for uncertainty analysis in LII measurements can be found in past works [37, 43, 99, 134-137]. Additional efforts should be directed to reducing the uncertainties of temperature measurements of NPs by pyrometry using the determination of $E(m)$ wavelength dependence by two laser pulses
(532 and $1064 \mathrm{~nm}$, respectively) and by avoiding high fluence regimes with onset evaporation control by extinction measurements.

\section{Conclusions}

Determining the properties of aerosol NPs is a complex problem connected to the small size of these nanoobjects. The refractive index function of the NP material, the thermal energy accommodation coefficient of the gas molecules on the NP surface and the evaporation temperature of NPs are important characteristics of nanomaterials. The methods of diagnostics based on NP sampling give or limit information (for example, size, structure, phase composition given by TEM analysis) or may be connected with uncertainties due to the pellets produced by pressing the nanomaterials (ex situ reflectometry measurements). The in situ optical methods allow for the investigation of the NP properties without sampling. The LII, the method of diagnostics used in a gas phase, employs the pulsed laser-heating method. Initially developed for the measurements of particle size and volume fraction, the LII can be used for NP property determination because the incandescence signals contain information about these properties, which can be extracted by using signal analysis. Until now, the pulsed laser heating method has only been applied for the determination of the refractive index function, the thermal energy accommodation coefficient and the evaporation NP temperature.

The measurements of the value of the refractive index function of Fe and carbon NPs were carried out on laser wavelengths of 1064 and $532 \mathrm{~nm}$ as part of the LII particle diagnostics. The refractive index function values of carbonaceous NPs were found to be between 0.05 and 0.4 and dependent on their size. The values of $E(m)$ for soot in flames with primary particle sizes of $20-50 \mathrm{~nm}$ range between 0.25 and 0.4 and presumably depend on flame conditions. Most $E(m)$ determination data for carbon NPs are in good agreement with the values reported by the extinction measurements, which range between 0.19 and 0.47 in the visible spectra. The deviation of the $E(m)$ measured values of soot could be a result of large uncertainties in the pyrometry temperature measurements, and in turn, these influence NP evaporation (even at low laser fluences). However, another explanation of this deviation is the differences in soot structure and composition (including impurities) formed under various conditions. The $E(m)$ values for Fe NPs were experimentally determined only at a wavelength of $1064 \mathrm{~nm}$ and were found to be between 0.1 and 0.2. It should be noted that these measurements 
should be performed at low laser fluences below the evaporation threshold. The same measurements could be carried out at wavelengths other than 1064 and $532 \mathrm{~nm}$ using available ns pulse laser systems. Future investigations could use two-laser wavelengths in experiments for the auto-correction of $E(m)$ wavelength dependence for arbitrary particles. The evaporation control by using laser light extinction or laser light scattering is also desirable.

The thermal energy accommodation coefficients of carbon and metal NPs with various gases can be evaluated by analyzing the LII decay rates of NPs of known size. At present, the LII is the sole in situ method for determining the accommodation coefficient of NPs dispersed in gas phase. A few studies using the LII showed that the thermal accommodation coefficient values depend on the molecular weight and type of bath gas. For carbon NPs in monoatomic gases, the thermal accommodation coefficient increased from 0.1 (in the case of $\mathrm{He}$ ) to 0.45 (in the case of $\mathrm{Xe}$ ). In polyatomic gases, much smaller values of thermal accommodation coefficients were detected (0.04-0.15). However, under flame conditions, a wide variation of thermal accommodation coefficient values was observed. This might be due to the different gas compositions resulting from the different fuel/air/combustion product ratios, which vary depending on the height above the burner. For Mo NPs in monoatomic gases, the thermal accommodation coefficient increased from 0.05 (in the case of $\mathrm{He}$ ) to 0.25 (in the case of Ar). For Fe NPs in monoatomic gases, the value of 0.01 (in the case of He) increased to 0.2 (in the case of Xe). In polyatomic gases with Fe NPs, the smaller values of thermal accommodation coefficients (0.07-0.2) were detected. The obtained data on the accommodation coefficient of soot and metal NPs were in an agreement with the molecular dynamic calculations. It was shown, that the determination of the accommodation coefficient of soot in various gases from LII measurements was most sensitive to perturbations in particle density, heat capacity and particle size. The uncertainties of determination of accommodation coefficient attain $\pm 50 \%$. In order to achieve more accurate accommodation coefficient determination by LII, the independent method of particle sizing with minimal error is needed. Further efforts in determining the thermal accommodation coefficient by LII should focus on the influence of gas and particle temperatures on the measurement results, the variation of the particle and gas types and the development of alternative particle sizing techniques.

The thermodynamic properties of NPs differ from the properties of other bulk materials due to the size effect. In addition, the sublimation/evaporation temperature variation of arbitrary NPs can be influenced by the variation in the crystalline structure, shape and presence of impurities. In the LII literature, the values of NP peak temperature were determined by two-color pyrometry at maximal LII signal amplitude. The evaporation temperature was defined by a plateau in the peak temperature/ fluence curve and this was further supported by observations of the volume fraction of the condensed phase drop during laser pulse, measured by laser light extinction measurements. The sublimation temperature of the carbonaceous NPs ranged from 3100 to 4500 and was dependent on the NP sizes and their formation conditions. The evaporation temperature of metal NPs during pulsed laser heating ranged from 2100 to $3100 \mathrm{~K}$ (for Fe NPs), 2800-5300 K (for Mo NPs), $4500 \mathrm{~K}$ (for silica NPs), $2800 \mathrm{~K}$ (for Ag NPs) and 2770-3100 K (for carbon-encapsulated Fe NPs). The large variations in the experimental data for metal NPs are caused by the non-thermal emission during laser pulsing at high fluences, as well as the varying interpretations of optical properties changing with wavelength, particle sizes and particle compositions (taking into account different probable impurities). The sublimation/evaporation temperature could be analyzed for the investigation of a size dependence of NP thermodynamic properties using universal relations presented in literature. Additional efforts should be directed to decrease the uncertainties of temperature measurements of NPs by pyrometry using the determination of $E(m)$ wavelength dependence by two laser pulses (532 and $1064 \mathrm{~nm}$ ) and avoiding high fluence regimes with the onset evaporation control by extinction measurements. Finally, the method of pulsed laser heating up to incandescence temperature is a promising in situ technique for investigating the unknown properties of lightabsorbing NPs dispersed in the gas phase.

Acknowledgments: This work was supported by the Russian Science Foundation (Funder Id: 10.13039/501100006769, project №14-50-00124).

\section{References}

[1] Michelsen HA, Schulz C, Smallwood GJ, Will S. Laser-induced incandescence: particulate diagnostics for combustion, atmospheric, and industrial applications. Prog. Energy Combust. Sci. 2015, 51, 2-48.

[2] Michelsen HA. Understanding and predicting the temporal response of laser-induced incandescence from carbonaceous particles. J. Chem. Phys. 2003, 118, 7012-7045.

[3] Liu F, Daun KJ, Snelling DR, Smallwood G]. Heat conduction from a spherical nanoparticle: status of modeling heat conduction in laser-induced incandescence. Appl. Phys. B 2006, 83, 355-382. 
[4] Smallwood GJ, Snelling DR, Liu F, Gülder ÖL. Clouds over soot evaporation: errors in modeling laser-induced incandescence of soot. Transactions of the ASME 2001, 123, 814-818.

[5] Mansmann R, Terheiden T, Schmidt P, Menser J, Dreier T, Endres T, Schulz C. LIISim - a modular signal processing toolbox for laser-induced incandescence measurements. Appl. Phys. B 2018, 124, 69.

[6] Sorensen CM. Light scattering by fractal aggregates: a review. Aerosol Sci. Technol. 2001, 35, 648-687.

[7] Bond TC, Bergstrom RW. Light absorption by carbonaceous particles: an investigative review. Aerosol Sci. Technol. 2006, 40, 27-67.

[8] Michel B, Henning Th, Jager C, Kreibig U. Optical extinction by spherical carbonaceous particles. Carbon 1999, 37, 391-400.

[9] Andreae MO, Gelencser A. Black carbon or brown carbon? The nature of light-absorbing carbonaceous aerosols. Atmos. Chem. Phys. 2006, 6, 3131-3148.

[10] Tregrossi A, Barbella R, Ciajolo A, Alfè M. Spectral properties of soot in the UV-visible range. Combust. Sci. Tech. 2007, 179, 371-385.

[11] Shvarev KM, Baum BA, Kudryavtsev VA, Baituraev SX. The influence of temperature of magnetic and phase transitions on iron optical properties. Teplofizika Vysokih Temperatur 1985, 23(3), 492-499.

[12] Galashev AE, Rakhmanova OR. Temperature changes of the optical properties of $\left(\mathrm{SiO}_{2}\right)_{n},(\mathrm{GaAs})_{\mathrm{m}}$, and $\left(\mathrm{SiO}_{2}\right)_{n}(\mathrm{GaAs})_{\mathrm{m}}$ nanoparticles: computer experiment. High Temperature 2013, 51(1), 97-105.

[13] Dobbins RA, Mulholland GW, Bryner NP. Comparison of a fractal smoke optics model with light extinction measurements. Atmos. Environ. 1994, 28(5), 889-897.

[14] Dalzell WH, Sarofim AF. Optical constants of soot and their application to heat-flux calculations. J. Heat Transf. 1969, 91, 100-104.

[15] Felske, JD, Charalampopoulos TT, Hura H. Determination of the refractive indices of soot particles from the reflectivities of compressed soot pellets. Combust. Sci. Technol. 1984, 37, 263-284.

[16] Stagg BJ, Charalampopoulos TT. Refractive indices of pyrolytic graphite, amorphous carbon and flame soot in the temperature range $25^{\circ}$ to $600^{\circ} \mathrm{C}$. Combust. Flame 1993, 94, 381-396.

[17] Köylü ÜÖ, Faeth GM. Spectral extinction coefficients of soot aggregates from turbulent diffusion flames. ASME J. Heat Transfer 1996, 118, 415-421.

[18] Wu J-S, Krishnan SS, Faeth GM. Refractive indices at visible wavelengths of soot emitted from buoyant turbulent diffusion flames. ASME J. Heat Transfer 1997, 119, 230-237.

[19] Krishnan SS, Lin KC, Faeth GM. Optical properties in the visible of overfire soot in large buoyant turbulent diffusion flames. ASME J. Heat Transfer 2000, 122, 517-524.

[20] Marley NA, Gaffney JS, Baird JCh, Blazer CA, Drayton PJ, Frederick JE. An empirical method for the determination of the complex refractive index of size-fractionated atmospheric aerosols for radiative transfer calculations. Aerosol Sci. Tech. 2001, 34, 535-549.

[21] Schnaiter M, Horvath H, Mohler O, Naumann K-H, Saathoff H, Schock OW. UV-VIS-NIR spectral optical properties of soot and soot-containing aerosols. J. Aerosol Sci. 2003, 34, 1421-1444.
[22] Thomson KA, Johnson MR, Snelling DR, Smallwood GJ. Diffuse-light two-dimensional line-of-sight attenuation for soot concentration measurements. Appl. Optics. 2008, 47, 694-703.

[23] Daun K, Menser J, Mansmann R, Dreier T, Schulz C. Spectroscopic models for laser-heated silicon and copper nanoparticles. J. Quant. Spectr. Rad. Transf. 2017, 197, 3-11.

[24] Krishnan SS, Lin K-C, Faeth GM. Extinction and scattering properties of soot emitted from buoyant turbulent diffusion flames. J. Heat Transf. 2001, 123, 331-339.

[25] Van-Hulle P, Talbaut M, Weill M, Coppalle A. Inversion method and experiment to determine the soot refractive index: application to turbulent diffusion flames. Meas. Sci. Technol. 2002, 13, 375-382.

[26] Kock B, Kayan C, Knipping J, Ortner HR, Roth P. Comparison of LII and TEM sizing during synthesis of iron particle chains. Proc. Combust. Inst. 2004, 30, 1689-1697.

[27] Snelling DR, Liu F, Smallwood GJ. Determination of the soot absorption function and thermal accommodation coefficient using low-fluence LII in a laminar coflow ethylene diffusion flame. Combust. Flame 2004, 136, 180-190.

[28] Snelling DR, Thomson KA, Smallwood GJ, Gülder ÖL, Weckman EJ, Fraser RA. Spectrally resolved measurement of flame radiation to determine soot temperature and concentration. AIAAJ. 2002, 40, 1789-1795.

[29] Chang H, Charalampopoulos TT. Determination of the wavelength dependence of refractive indices of flame soot. Proc. $R$. Soc. London, Ser. A 1990, 430, 577-591.

[30] Michelsen HA, Schrader PE, Goulay F. Wavelength and temperature dependences of the absorption and scattering cross sections of soot. Carbon 2010, 48, 2175-2191.

[31] Snelling D, Thomson K, Liu F, Smallwood G. Comparison of LII derived soot temperature measurements with LII model predictions for soot in a laminar diffusion flame. Appl. Phys. B 2009, 96, 657-669.

[32] De Iuliis S, Migliorini F, Cignoli F, Zizak G. Peak soot temperature in laser induced incandescence measurements. Appl. Phys. B 2006, 83, 397-402.

[33] Eremin AV, Gurentsov EV, Popova E, Priemchenko K. Size dependence of complex refractive index function of growing nanoparticles. Appl. Phys. B 2011, 104, 285-295.

[34] Mulholland GW, Choi MY. Measurement of the mass specific extinction coefficient for acetylene and ethene smoke using the large agglomerate optics facility. Proc. Combust. Inst. 1998, 27, 1515-1122.

[35] Zhu J, Choi MY, Mulholland GW, Gritzo LA. Soot scattering measurements in the visible and near-infrared spectrum. Proc. Combust. Inst. 2000, 28, 439-446.

[36] Iyer SS, Litzinger TA, Lee S-Y, Santoro RJ. Determination of soot scattering coefficient from extinction and three-angle scattering in a laminar diffusion flame. Combust. Flame 2008, 149, 206-216.

[37] Sipkens TA, Mansmann R, Daun KJ, Petermann N, Titantah JT, Karttunen M, Wiggers H, Dreier T, Schulz C. In situ nanoparticle size measurements of gas-borne silicon nanoparticles by timeresolved laser-induced incandescence. Appl. Phys. B 2014, 116, 623-636.

[38] Menser J, Daun KJ, Dreier T, Schulz C. Laser-induced atomic emission of silicon nanoparticles during laser-induced heating. Appl. Opt. 2017, 56, E50-E57. 
[39] Sipkens TA, Singh NR, Daun KJ. Time-resolved laser-induced incandescence characterization of metal nanoparticles. Appl. Phys. B 2017, 123, 14.

[40] Gurentsov EV. UV laser synthesis of nanoparticles in the gas phase. Kinet. Catalysis 2017, 58(3), 233-254.

[41] Gurentsov E, Eremin A. Size measurement of carbon and iron nanoparticles by laser induced incandescence. High Temperature 2011, 49(5), 667-673.

[42] Palik, ED. Handbook of optical constants of solids, Academic Press: New York, 1991.

[43] Sipkens TA, Singh NR, Daun KJ, Bizmark N, loannidis M. Examination of the thermal accommodation coefficient used in the sizing of iron nanoparticles by time-resolved laser-induced incandescence. Appl. Phys. B 2015, 119, 561-575.

[44] Krishnan S, Yugawa KJ, Nordine PC. Optical properties of liquid nickel and iron. Phys. Rev. B 1997, 55, 8201-8206.

[45] Miller JC. Optical properties of liquid metals at high temperatures. Philos. Mag. 1969, 20(168), 1115-1132.

[46] Shvarev KM, Gushchin VS, Baum B. The effect of temperature on optical constants of iron. High Temperature 1978, 16(3), 441-446.

[47] Kobatake H, Khosroabadi H, Fukuyama H. Normal spectral emissivity measurement of liquid iron and nickel using electromagnetic levitation in direct current magnetic field. Metall. Mater. Trans. A 2012, 43A, 2466-2472.

[48] Daun KJ. Discussion of "Normal spectral emissivity measurement of liquid iron and nickel using electromagnetic levitation in direct current magnetic field". Metall. Mater. Trans. A 2016, 47, 3300-3302.

[49] Vander Wal RL. Onset of carbonization: spatial location via simultaneous LIF-LII and characterization via TEM. Combust. Sci. Technol. 1996, 118, 343-360.

[50] Vander Wal RL, Ticich TM, Stephens AB. Optical and microscopy investigations of soot structure alterations by laserinduced incandescence. Appl. Phys. B 1998, 67, 115-123.

[51] Vander Wal RL, Choi MY. Pulsed laser heating of soot: morphological changes. Carbon 1999, 37, 231-239.

[52] Vander Wal RL. Laser-induced incandescence: excitation and detection conditions, material transformations, and calibration. Appl. Phys. B 2009, 96, 601-611.

[53] Cenker E, Roberts WL. Quantitative effects of rapid heating on soot-particle sizing through analysis of two-pulse LII. Appl. Phys. B 2017, 123, 74.

[54] Cenker E, Bennett A, Roberts WL. Investigations of the longterm effects of LII on soot and bath gas. Aerosol Sci. Tech. 2017, 51, 1354-1367.

[55] Eckbreth AC. Effect of laser-modulated particulate incandescence on Raman scattering diagnostics. J. Appl. Phys. 1977, 48, 4473-4479.

[56] Dasch CJ. Continuous-wave probe laser investigation of laser vaporization of small soot particles in a flame. Appl. Opt. 1984, 23, 2209-2215.

[57] Witze PO, Hochgreb S, Kayes D, Michelsen HA, Shaddix CR. Time-resolved laser-induced incandescence and laser elastic scattering measurements in a propane diffusion flame. Appl. Opt. 2001, 40, 2443-2452.

[58] Yoder GD, Diwaker PK, Hahn DW. Assessment of soot particle vaporization effects during laser-induced incandescence with time-resolved light scattering. Appl. Opt. 2005, 44, 4211-4219.
[59] Krüger V, Wahl C, Hadef R, Geigle KP, Stricker W, Aigner M. Comparison of laser-induced incandescence method with scanning mobility particle sizer technique: the influence of probe sampling and laser heating on soot particle size distribution. Meas. Sci. Technol. 2005, 16, 1477-1486.

[60] Michelsen HA, Tivanski AV, Gilles MK, van Poppel LH, Dansson MA, Buseck PR. Particle formation from pulsed laser irradiation of soot aggregates studied with a scanning mobility particle sizer, a transmission electron microscope, and a scanning transmission x-ray microscope. Appl. Opt. 2007, 46, 959-977.

[61] Eremin A, Gurentsov E, Mikheyeva E, Priemchenko K. Experimental study of carbon and iron nanoparticle vaporization under pulse laser heating. Appl. Phys. B 2013, 112, 421-432.

[62] Therssen E, Bouvier Y, Schoemaecker-Moreau C, Mercier X, Desgroux P, Ziskind $M$, Focsa $C$. Determination of the ratio of soot refractive index function $\mathrm{E}(\mathrm{m})$ at the two wavelengths 532 and $1064 \mathrm{~nm}$ by laser induced incandescence. Appl. Phys. B 2007, 89, 417-427.

[63] Goodman, FO, Wachman HY. Dynamics of Gas-Surface Scattering, Academic Press: New York, 1976.

[64] Goodman FO. Thermal accommodation. Prog. Surf. Sci. 1974, 5, 261-375.

[65] Michelsen HA. Derivation of a temperature-dependent accommodation coefficient for use in modeling laser-induced incandescence of soot. Appl. Phys. B 2009, 94, 103-117.

[66] Leroy O, Perrin J, Jolly J, Pealat M, Lefebvre M. Thermal accommodation of a gas on a surface and heat transfer in CVD and PECVD experiments. J. Phys. D Appl. Phys. 1997, 30, 499-509.

[67] Bladh H, Johnsson J, Rissler J, Abdulhamid H, Olofsson N-E, Sanati M, Pagels J, Bengtsson P-E. Influence of soot particle aggregation on time-resolved laser-induced incandescence signals. Appl. Phys. B 2011, 104, 331-341.

[68] Kuhlmann S, Reimann J, Will S. On heat conduction between laser-heated nanoparticles and a surrounding gas. J. Aerosol Sci. 2006, 37, 1696-1716.

[69] Liu F, Yang M, Hill FA, Snelling DR, Smallwood GJ. Influence of polydisperse distributions of both primary particle and aggregate size on soot temperature in low-fluence LII. Appl. Phys. B 2006, 83, 383-395.

[70] Filippov AV, Zurita M, Rosner DE. Fractal-like aggregates: relation between morphology and physical properties. J. Colloid Interface Sci. 2000, 229, 261-273.

[71] Liu F, Smallwood GJ. The effect of particle aggregation on the absorption and emission properties of mono- and polydisperse soot aggregates. Appl. Phys. B 2011, 104, 343-355.

[72] Liu F, Smallwood GJ, Snelling DR. Effects of primary particle diameter and aggregate size distribution on the temperature of soot particles heated by pulsed lasers. J. Quant. Spectr. Radiat. Transf. 2005, 93, 301-312.

[73] Bladh H, Johnsson J, Bengtsson P-E. On the dependence of the laser-induced incandescence (LII) signal on soot volume fraction for variations in particle size. Appl. Phys. B 2008, 90, 109-125.

[74] Bambha RP, Dansson MA, Schrader PE, Michelsen HA. Effects of volatile coatings on the laser-induced incandescence of soot. Appl. Phys. B 2013, 112, 343-358.

[75] Bambha RP, Michelsen HA. Effects of aggregate morphology on size and laser-induced incandescence and scattering from black carbon (mature soot). J. Aerosol Sci. 2015, 88, 159-181. 
[76] Bladh H, Johnsson J, Bengtsson P-E. Influence of spatial laser energy distribution on evaluated soot particle sizes using two-colour laser-induced incandescence in a flat premixed ethylene/air flame. Appl. Phys. B 2009, 96, 645-656.

[77] Lopez-Yglesias X, Schrader PE, Michelsen HA. Soot maturity and absorption cross sections. J. Aerosol Sci. 2014, 75, 43-64.

[78] Maffi S, De luliis S, Cignoli F, Zizak G. Investigation on thermal accommodation coefficient and soot absorption function with two-color Tire-LII technique in rich premixed flames. Appl. Phys. B 2011, 104, 357-366.

[79] Bladh H, Johnsson J, Olofsson NE, Bohlin A, Bengtsson PE. Optical soot characterization using two-color laser-induced incandescence (2C-LII) in the soot growth region of a premixed flat flame. Proc. Combust. Inst. 2011, 33, 641-648.

[80] Starke R, Kock B, Roth P. Nano-particle sizing by laser-inducedincandescence (LII) in a shock wave reactor. Shock Waves 2003, 12, 351-360.

[81] Eremin AV, Gurentsov EV, Hofmann M, Kock BF, Schulz C. TR-LII for sizing of carbon particles forming at room temperature. Appl. Phys. B 2006, 83, 449-454.

[82] Daun K, Smallwood G, Liu F. Investigation of thermal accommodation coefficients in time-resolved laser-induced incandescence. J. Heat Transf. 2008, 130, 121201.

[83] Daun KJ. Thermal accommodation coefficients between polyatomic gas molecules and soot in laser-induced incandescence experiments. Int. J. Heat and Mass Transf. 2009, 52, 5081-5089.

[84] Daun KJ. Effect of selective accommodation on soot aggregate shielding in time-resolved laser-induced incandescence experiments. J. Heat Transf. 2010, 132, 091202.

[85] Elihn K, Landström L, Heszler P. Emission spectroscopy of carbon covered iron nanoparticles in different gas atmospheres. Appl. Surf. Sci. 2002, 186, 573-577.

[86] Landström L, Elihn K, Boman M, Granqvist CG, Heszler P. Analysis of thermal radiation from laser-heated nanoparticles formed by laser-induced decomposition ferrocene. Appl. Phys. A 2005, 81, 827-833.

[87] Eremin AV, Gurentsov EV, Schulz C. Influence of the bath gas on the condensation of supersaturated iron atom vapor at room temperature. J. Phys. D: Appl. Phys. 2008, 41, 055203.

[88] Daun KJ, Sipkens TA., Titantah JT, Karttunen M. Thermal accommodation coefficients for laser-induced incandescence sizing of metal nanoparticles in monatomic gases Appl. Phys. B 2013, 112, 409-420.

[89] Krajnovich DJ. Laser sputtering of highly oriented pyrolytic graphite at $248 \mathrm{~nm}$. J. Chem. Phys. 1995, 102, 726-743.

[90] Fuchs NA. Evaporation and Droplet Growth in Gaseous Media, Pergamon Press: London, 1959.

[91] Anisimov SI. Vaporization of metal absorbing laser radiation. Sov. Phys. JETP 1968, 27, 182-183.

[92] Phipps CR, Dreyfus RW. The high laser irradiance regime. In Laser Ionization Mass Analysis, Vertes A, Gijbels R, Adams F, Eds., Wiley: New York, 1993, pp. 369-431.

[93] Agranat MB, Andreev NE, Ashitkov SI, Emelianov AV, Eremin AV, Gurentsov EV, Ovchinnikov AV, Sitnikov DS. Interaction of intense femtosecond laser pulses with iron clusters formed by photo-dissociation of $\mathrm{Fe}(\mathrm{CO})_{5}$. Proc. of SPIE "Topical Problems of Nonlinear Wave Physics" 2006, 5975, 35-42.

[94] Murakami Y, Sugatani T, Nosaka Y. Laser-induced incandescence study on the metal aerosol particles as the effect of the surrounding gas medium. J. Phys. Chem. A 2005, 109, 8994-9000.

[95] Goulay F, Schrader PE, Nemes L, Dansson MA, Michelsen HA. Photochemical interferences for laser-induced incandescence of flame-generated soot. Proc. Combust. Inst. 2009, 32, 963-970.

[96] Zhang Y, Li S, Ren Y, Yao Q, Tse SD. A new diagnostic for volume fraction measurement of metal-oxide nanoparticles in flames using phase-selective laser-induced breakdown spectroscopy. Proc. Combust. Inst. 2015, 35, 3681-3688.

[97] Zhang Y, Xiong G, Li S, Dong Z, Buckley SG, Tse SD. Novel lowintensity phase-selective laser-induced breakdown spectroscopy of $\mathrm{TiO}_{2}$ nanoparticle aerosols during flame synthesis. Combust. Flame 2013, 160, 725-733.

[98] Xu X, Willis DA. Non-equilibrium phase change in metal induced by nanosecond. Pulsed laser irradiation. J. Heat Transf. 2002, 124, 293-298.

[99] Menser J, Daun K, Dreier T, Schulz C. Laser-induced incandescence from laser heated silicon nanoparticles. Appl. Phys. B 2016, 122, 277.

[100] Ni T, Pinson JA, Gupta S, Santoro RJ. Two-dimensional imaging of soot volume fraction by the use of laser-induced incandescence. Appl. Opt. 1995, 34, 7083-7091.

[101] Goulay F, Schrader PE, Michelsen HA. Effect of the wavelength dependence of the emissivity on inferred soot temperatures measured by spectrally resolved laser-induced incandescence. Appl. Phys. B 2010, 100, 655-663.

[102] Liu F, Snelling D, Thomson K, Smallwood G. Sensitivity and relative error analyses of soot temperature and volume fraction determined by two-color LII. Appl. Phys. B 2009, 96, 623-636.

[103] Olofsson N-E, Simonsson J, Török S, Bladh H, Bengtsson P-E. Evolution of properties of aging soot in premixed flat flames studied by laser-induced incandescence and elastic light scattering. Appl. Phys. B 2015, 119, 669-683.

[104] Schulz C, Kock BF, Hofmann M, Michelsen HA, Will S, Bougie $B$, Suntz R, Smallwood G. Laser-induced incandescence: recent trends and current questions. Appl. Phys. B 2006, 83, 333-354.

[105] Schraml S, Dankers S, Bader K, Will S, Leipertz A. Soot temperature measurements and implications for time-resolved laser-induced incandescence (TIRE-LII). Combust. Flame 2000, 120, 439-450.

[106] Lehre T, Jungfleisch B, Suntz R, Bockhorn H. Size distributions of nanoscaled particles and gas temperatures from timeresolved laser-induced-incandescence measurements. Appl. Opt. 2003, 42, 2021-2030.

[107] Bougie B, Ganippa LC, Dam NJ, Ter Meulen JJ. On particulate characterization in a heavy-duty diesel engine by timeresolved laser-induced incandescence. Appl. Phys. B 2006, 83, 477-485.

[108] Olofsson N-E, Johnsson J, Bladh H, Bengtsson P-E. Soot sublimation studies in a premixed flat flame using laser-induced incandescence (LII) and elastic light scattering (ELS). Appl. Phys. B 2013, 112, 333-342.

[109] Goulay F, Schrader PE, Lopez-Yglesias X, Michelsen HA. A data set for validation of models of laser-induced incandescence from soot: temporal profiles of LII signal and particle temperature. Appl. Phys. B 2013, 112, 287-306. 
[110] Whittaker GA. The controversial carbon solid-liquid-vapor triple point. Nature 1978, 276, 695-697.

[111] Boiarciuc A, Foucher F, Mounaim-Rousselle C. Soot volume fractions and primary particle sizeestimate by means of the simultaneous two-color-time-resolved and 2D laser-induced incandescence. Appl. Phys. B 2006, 83, 413-421.

[112] Desai PD. Thermodynamic properties of iron and silicon. J. Phys. Chem. Ref. Data 1986, 15, 967-983.

[113] Desai PD. Thermodynamic properties of manganese and molybdenum. J. Phys. Chem. Ref. Data 1987, 16, 91-108.

[114] Eremin AV, Gurentsov EV. Sizing of Mo nanoparticles synthesized by $\mathrm{Kr}-\mathrm{F}$ laser pulse photo-dissociation of $\mathrm{Mo}(\mathrm{CO})_{6}$. Appl. Phys. A 2015, 119, 615-622.

[115] Eremin AV, Gurentsov EV, Musikhin SA. Synthesis of binary iron-carbon nanoparticles by UV laser photolysis of $\mathrm{Fe}(\mathrm{CO})_{5}$ with various hydrocarbons. Mater. Res. Express 2016, 3, 105041.

[116] Gurentsov EV, Eremin AV, Mikheyeva EYu, Musikhin SA. Anomalous behavior of optical density of iron nanoparticles heated behind shock waves. High Temperature 2016, 54, 896-898.

[117] Eremin AV, Gurentsov EV, Musikhin SA. Diagnostics of carbon covered iron nanoparticles by laser heating. J. Phys. Conf. Ser. 2018, 946, 012068.

[118] Eremin A. Formation of carbon nanoparticles from the gas phase in shock wave pyrolysis processes. Prog. Energy Combust. Sci. 2012, 38, 1-40.

[119] Nanda KK, Kruis FE, Fissan H. Evaporation of free PbS nanoparticles: evidence of the Kelvin effect. Phys. Rew. Letters 2002, 89, 256103.

[120] Mansmann R, Dreier T, Schulz C. Performance of photomultipliers in the context of laser-induced incandescence. Appl. Opt. 2017, 56, 7849-7860.

[121] Hendy SC. A thermodynamic model for the melting of supported metal nanoparticles. Nanotechnology 2007, 18, 175703.

[122] Ding F, Bolton K, Rosen A. Iron-carbide cluster thermal dynamics for catalyzed carbon nanotube growth. J. Vac. Sci. Technol. A 2004, 22, 1471-1476.

[123] Ding F, Bolton K, Rosen A. Size dependence of the coalescence and melting of iron clusters: a molecular-dynamics study. Phys. Rev. B 2004, 70, 075416-1.

[124] Lihachev VN, Astahova TYu, Vinogradov GA, Aliymov MI. Anomalous heat capacity of nanoparticles. Russian J. Phys. Chem. B 2007, 1, 74-78.

[125] Nanda KK, Maisels A, Kruis FE, Fissan H, Stappert S. Higher surface energy of free nanoparticles. Phys. Rev. Lett. 2003, 91, 106102.

[126] Wang TH., Zhu YF, Jiang Q. Size effect on evaporation temperature of nanocrystals. Mater. Chem. Phys. 2008, 111, 293-295.

[127] Xiong S, Qi W, Cheng Y, Huang B, Wang M. Universal relation for size dependent thermodynamic properties of metallic nanoparticles. Phys. Chem. Chem. Phys. 2011, 13, 10652-10660.

[128] Nanda KK. Bulk cohesive energy and surface tension from the size-dependent evaporation study of nanoparticles. Appl. Phys. Lett. 2005, 87, 021909.

[129] Cui, ZX, Zhao MZ, Lai WP, Xue YQ. Thermodynamics of size effect on phase transition temperatures of dispersed phases. J. Phys. Chem. C 2011, 115, 22796-22803.

[130] Yu X, Zhan Z. The effects of the size of nanocrystalline materials on their thermodynamic and mechanical properties. Nanoscale Res. Lett. 2014, 9, 516-522.
[131] Gurentsov EV, Eremin AV, Mikheyeva EYu. Study of thermodynamic properties of carbon nanoparticles by the laser heating method. High Temperature 2017, 55, 723-730.

[132] Will S, Schraml S, Bader K, Leipertz A. Performance characteristics of soot primary particle size measurements by time-resolved laser-induced incandescence. Appl. Opt. 1998, 37, 5647-5658.

[133] Crosland BM, Johnson MR, Thomson KA. Analysis of uncertainties in instantaneous soot volume fraction measurements using two-dimensional, auto-compensating, laser-induced incandescence (2D-AC-LII). Appl. Phys. B 2011, 102, 173-183.

[134] Hadwin PJ, Sipkens TA, Thomson KA, Liu F, Daun KJ. Quantifying uncertainty in auto-compensating laser-induced incandescence parameters due to multiple nuisance parameters. Appl. Phys. B 2017, 123, 114-128.

[135] Hadwin PJ, Sipkens TA, Thomson KA, Liu F, Daun KJ. Quantifying uncertainty in soot volume fraction estimates using Bayesian inference of auto-correlated laser-induced incandescence measurements. Appl. Phys. B 2016, 122, 1-16.

[136] Hadwin PJ, Sipkens TA, Thomson KA, Liu F, Daun KJ. Kalman filter approach for uncertainty quantification in time-resolved laserinduced incandescence. J. Opt. Soc. Amer. A 2018, 35, 386-396.

[137] Sipkens TA, Hadwin PJ, Grauer SJ, Daun KJ. General error model for analysis of laser-induced incandescence signals. Appl. Opt. 2017, 56, 8436-8445.

\section{Bionote}

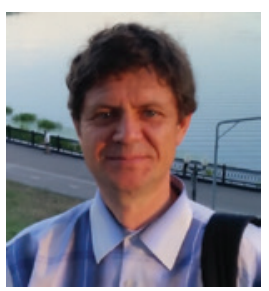

\section{Evgeny Valerievich Gurentsov}

Joint Institute for High Temperatures, Russia Academy of Sciences, 125412 Izhorskaya St. 13-2, Moscow, Russia, gurentsov@ihed.ras.ru

Evgeny Valerievich Gurentsov, $\mathrm{PhD}$, is a senior researcher at the Laboratory of Non-Equilibrium Processes of the Joint Institute for High Temperature, Russian Academy of Sciences, Moscow, Russia. Dr. Gurentsov graduated from the Moscow Aviation Institute in 1990. His PhD work was connected with the experimental investigation of heat transfer in the turbulent boundary layer at high temperatures. Dr. Gurentsov earned his PhD in Thermo-Physical Engineering from the Joint Institute for High-Temperature Research in 1995. In 2003, Dr. Gurentsov was awarded the INTAS Young Scientist Fellowship for a postdoctoral position and worked in collaboration with professors from the University of Heidelberg and University of DuisburgEssen, Germany. His major areas of research interest include the heat-transfer processes in shock-heated gases, gas-particle heat transfer, gas-phase metallic and carbonaceous nanoparticle synthesis, photo-dissociation of carbon and metal bearing species with following clusters and nanoparticle formation, and laser-based nanoparticle diagnostics. First, in Russia, Dr. Gurentsov developed LII diagnostics for nanoparticle sizing and for investigating nanoparticle properties. Dr. Gurentsov is a leader in developing nanoparticle synthesis methods by the UV photo-dissociation of gaseous precursors. He has co-authored more than 50 research papers in international journals and conferences. 